\title{
Evidence-based clinical practice guidelines for cholelithiasis 2016
}

\author{
Susumu Tazuma ${ }^{1,2} \cdot$ Michiaki Unno $^{1} \cdot$ Yoshinori Igarashi $^{1} \cdot$ Kazuo Inui $^{1} \cdot$ \\ Kazuhisa Uchiyama $^{1} \cdot$ Masahiro Kai $^{1} \cdot$ Toshio Tsuyuguchi $^{1} \cdot$ Hiroyuki Maguchi $^{1}$ • \\ Toshiyuki Mori $^{1} \cdot$ Koji Yamaguchi $^{1} \cdot$ Shomei Ryozawa $^{1} \cdot$ Yuji Nimura $^{1}$. \\ Naotaka Fujita $^{1}$ - Keiichi Kubota ${ }^{1}$. Junichi Shoda ${ }^{1}$ Masami Tabata ${ }^{1}$. \\ Tetsuya Mine $^{1} \cdot$ Kentaro Sugano $^{1} \cdot$ Mamoru Watanabe $^{1} \cdot$ Tooru Shimosegawa $^{1}$
}

Received: 13 November 2016/ Accepted: 14 November 2016/Published online: 10 December 2016

(C) Japanese Society of Gastroenterology 2016

\begin{abstract}
Cholelithiasis is one of the commonest diseases in gastroenterology. Remarkable improvements in therapeutic modalities for cholelithiasis and its complications are evident. The Japanese Society of Gastroenterology has revised the evidence-based clinical practice guidelines for cholelithiasis. Forty-three clinical questions, for four categories-epidemiology and pathogenesis, diagnosis, treatments, and prognosis and complications-were selected, and a literature search was performed for the clinical questions with use of the MEDLINE, Cochrane, and Igaku Chuo Zasshi databases for the period between 1983 and June 2012. The guidelines were developed with use of the Grading of Recommendations Assessment, Development, and Evaluation (GRADE) system. This article preferentially describes the clinical management of cholelithiasis and its complications. Following description of the diagnosis performed stepwise through imaging modalities, treat-
\end{abstract}

The original version of this article appeared in Japanese as

"Tansekishou Shinryo Guidelines 2016" from the Japanese Society of Gastroenterology, published by Nankodo, Tokyo, 2016. See the article on the standards, methods, and process of developing the guidelines (doi:10.1007/s00535-014-1016-1).

The members of the Guidelines Committee are listed in the Appendix.

Susumu Tazuma

stazuma@hiroshima-u.ac.jp

1 Guidelines Committee for the Japanese Society of Gastroenterology "Evidence-based clinical practice guidelines for cholelithiasis", Hiroshima, Japan

2 Department of General Internal Medicine, Hiroshima University Hospital, Graduate School of Medicine, 1-2-3, Kasumi, Minami-ku, Hiroshima 734-8551, Japan ments of cholecystolithiasis, choledocholithiasis, and hepatolithiasis are introduced along with a flowchart. Since there have been remarkable improvements in endoscopic treatments and surgical techniques, the guidelines ensure flexibility in choices according to the actual clinical environment. The revised clinical practice guidelines are appropriate for use by clinicians in their daily practice.

Keywords Cholelithiasis · Laparoscopic cholecystectomy · Bile acid dissolution therapy · Extracorporeal shock wave lithotripsy $\cdot$ Endoscopic sphincterotomy

\section{Introduction}

The first edition of "Clinical practice guidelines for the treatment of cholelithiasis," published in 2009, was developed on the basis of documented evidence published from 1983 to 2007 and consisted of chapters on epidemiology and pathology, diagnosis, treatments (separate sections for cholecystolithiasis, choledocholithiasis, and hepatolithiasis), and prognosis and complications. However, for topics in the chapter on epidemiology and pathology, there was little evidence during the search period, leaving no choice but to refer mostly to classic documentation. In subsequent years, however, remarkable advancements in medical equipment, such as endoscopic devices, and an increase in epidemiological research in Japan and overseas resulted in a suitable opportunity to revise the guidelines on the basis of new evidence. Thus, "Evidence-based clinical practice guidelines for the treatment of cholelithiasis (2nd revised ed.)" for actual clinical practice was developed through cooperation between the 
Japan Gastroenterological Endoscopy Society and the Japan Biliary Association.

A working committee (Chair, S. Tazuma; Vice-Chair, M. Unno; Y. Igarashi, K. Inui, K. Uchiyama, M. Kai, T. Tsuyuguchi, H. Maguchi, T. Mori, K. Yamaguchi, and S. Ryozawa) and an evaluation committee (Chair, Y. Nimura; Vice-Chair, N. Fujita; K. Kubota, J. Shoda, M. Tabata, and T. Mine) collaborated to create the guidelines. The revised guidelines consist of sections on epidemiology and pathology, diagnosis, treatments (separate sections for cholecystolithiasis, choledocholithiasis, and hepatolithiasis), and prognosis and complications. Fortythree clinical questions (CQs) were selected, and a literature search was performed for the CQs with use of the MEDLINE, Cochrane, and Igaku Chuo Zasshi databases for the period between 1983 and June 2012. The guidelines were developed with use of the Grading of Recommendations Assessment, Development, and Evaluation (GRADE) system [1]. The quality of evidence was graded as A (high), B (moderate), C (low), or D (very low). The strength of a recommendation was indicated as either 1 (strong recommendation) or 2 (weak recommendation). Consensus was previously defined as $70 \%$ or more votes in agreement [1].

This article preferentially describes the clinical management of cholelithiasis and its complications by summarizing CQs. Treatments of cholecystolithiasis, choledocholithiasis, and hepatolithiasis are introduced along with a flowchart. The revised clinical practice guidelines are appropriate for use by clinicians in their daily practice.

\section{Diagnosis of cholelithiasis}

Diagnosis of cholelithiasis is performed by history taking, physical examination, blood examination, ultrasonography, and abdominal X-ray. The typical symptoms are abdominal or back pain, fever, nausea and/or vomiting, and jaundice. Biliary colic, a severe pain in the right upper quadrant, is less frequent, and many cases remain asymptomatic, incidentally diagnosed on screening by ultrasonography. For cases that are undefined, CT and/or magnetic resonance cholangiopancreatography (MRCP), and drip infusion cholangiography associated $\mathrm{CT}$ as the second-line modality should be performed. For cases still to be diagnosed, endoscopic retrograde cholangiopancreatography (ERCP), endoscopic ultrasonography, intraductal ultrasonography, and percutaneous transhepatic cholangiography are recommended. Diagnosis of cholelithiasis should be performed stepwise when undefined as shown in Fig. 1.

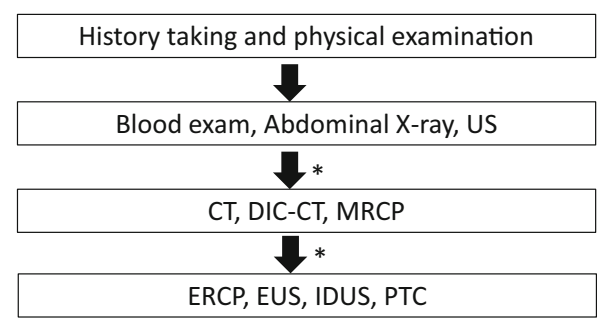

*should be proceeded step-wisely, when diagnosis undefined.

Fig. 1 Flowchart for diagnosis for cholelithiasis. Diagnosis in gallstone patients is performed by history taking, physical examination, blood examination, ultrasonography (US), and abdominal X-ray. For cases that are undefined, CT and/or magnetic resonance cholangiopancreatography (MRCP), and drip infusion cholangiography associated CT (DIC-CT), endoscopic retrograde cholangiopancreatography (ERCP), endoscopic ultrasonography (EUS), and intraductal ultrasonography (IDUS) should be performed for definitive diagnosis together with diagnosis of complications such as cholecystitis, cholangitis, liver abscess, and biliary cancers (see the text for details)

\section{Treatment of cholecystolithiasis}

\section{CQ1: Should asymptomatic cholecystolithiasis be treated?}

\section{Statement}

- We propose that asymptomatic patients should not be treated if the gallbladder wall is fully evaluable.

Strength of recommendation (agreement rate): 2 $(100 \%)$.

Evidence level: C.

- However, because hepatic dysfunction or gallbladder cancer can occur, annual follow-up including physical examination, abdominal ultrasonography, and other modalities judged appropriate is recommended.

Strength of recommendation (agreement rate): 2 $(100 \%)$.

Evidence level: C.

\section{Commentary}

Surgical treatment should be carefully selected for patients with asymptomatic cholecystolithiasis because of the likelihood of complications. Surgery is not recommended for patients with diabetes, for children, or for those with organ transplants $[2,3]$. About $2-4 \%$ of asymptomatic cholecystolithiasis patients become symptomatic during follow-up annually. Risk factors for transition include multiple gallstones, negative cholecystography findings, and young age [4-6]. There is no clear evidence that cholecystolithiasis increases the risk of gallbladder cancer or that there is an 
association of gallbladder cancer and cholelithiasis. Nevertheless, some studies have reported an increased risk of gallbladder cancer in patients with gallstones with a diameter of $3 \mathrm{~cm}$ or greater or porcelain gallbladder and in elderly women [4]. The overall annual incidence of gallbladder cancer during cholelithiasis follow-up is only $0.01-0.02 \%$, and about $0.3 \%$ in those followed up for 5 years or more. In light of this evidence, surgery is not recommended solely to prevent gallbladder cancer [7-13].

Accordingly, no treatment is necessary for patients whose gallbladder wall can be adequately evaluated by abdominal ultrasonography. However, annual follow-up assessment is recommended for such patients. In cases with a gallbladder filled with stones, negative cholecystography findings, or thickened gallbladder wall and suspected cancer, it is best to determine the surgical treatment on the basis of consultation with the patient even if no symptoms are observed.

\section{CQ2: What treatment is recommended for symptomatic cholecystolithiasis?}

\section{Statement}

- We recommend cholecystectomy for cholecystolithiasis patients presenting with any symptoms.

Strength of recommendation (agreement rate): 1 (100\%).

Evidence level: B.

- However, for patients who do not consent to surgery, we recommend oral dissolution therapy or extracorporeal shock wave lithotripsy (ESWL), if either is indicated.

Strength of recommendation (agreement rate): 2 (100\%).

Evidence level: B.

\section{Commentary}

Cholecystectomy is the first choice for treatment of symptomatic cholecystolithiasis, especially for patients with acute cholecystitis. Cholelithiasis is responsible for $90-95 \%$ of cases of acute cholecystitis, and $2 \%$ of patients with nonsevere cholecystitis experience a recurrence within 8-10 weeks [14]. Evidence from randomized trials on the benefits of cholecystectomy for treatment of acute cholecystitis shows that acute cholecystitis developed in $11 \%$ of followed-up cholelithiasis patients within 1.5-4 years, and 24\% underwent cholecystectomy [15]. Of 720 cholelithiasis patients with previous symptoms, the symptom-free period was 10 years or more in 41 patients $(5.7 \%)$ and 20 years or more in 26 patients $(3.6 \%)$. A sudden, serious recurrence after a long symptom-free period is not uncommon in elderly patients with cholelithiasis [16]. In a comparison of elderly cholelithiasis surgery patients aged 70 years or older with those younger than 70 years, acute cholecystitis complications occurred in $23.2 \%$ of the elderly patients versus $12.0 \%$ of the younger patients. Comorbidities were present in $30 \%$ of the elderly patients versus $9 \%$ of the younger patients, and other differences included emergency versus early surgery ( $22 \%$ vs $4 \%$ ), concomitant bile duct stones ( $47 \%$ vs $16 \%$ ), the rate of identification of bacteria in bile ( $80 \%$ vs $33 \%)$, postoperative complications ( $25 \%$ vs $9 \%$ ), and mortality ( $2.4 \%$ vs $0.6 \%$ ). Surgery is the treatment of choice for cholelithiasis in elderly patients with no severe comorbidities, but it is optimal to perform surgery during an intermission when acute cholangitis and obstructive jaundice are not involved, whenever possible [17].

For cholecystocholedocholithiasis, the recommendation for cholecystectomy after endoscopic treatment of choledocholithiasis is controversial. In a study of 61 patients with cholecystolithiasis, biliary tract pain emerged within 1 year in 12 patients $(19.7 \%)$, and 11 patients required cholecystectomy. Patients with gallstone diameters of $10 \mathrm{~mm}$ or greater or concomitant acute pancreatitis had an increased likelihood of undergoing cholecystectomy. Cholecystectomy should thus be strongly recommended for treatment of cholecystolithiasis after removal of common bile duct stones if the stone diameter is $10 \mathrm{~mm}$ or greater or if the patient has concomitant, acute pancreatitis [18].

Nonsurgical treatment with ursodeoxycholic acid (UDCA) has been reported to significantly reduce the risk of biliary tract pain, surgery, and acute cholecystitis even in symptomatic patients. UDCA is recommended for symptomatic patients who do not undergo surgery if dissolution therapy is indicated [19]. Treatment with ESWL in combination with dissolution therapy achieved complete elimination of gallstones in $87 \%$ of a group of symptomatic patients [20]. Therefore, it appears that this method of treatment makes it possible to achieve a high rate of elimination in a select group of patients [21, 22].

\section{CQ3: Is laparoscopic cholecystectomy the first- choice surgical option? What are the indications for open surgery?}

\section{Statement}

Is laparoscopic cholecystectomy the first-choice surgical option?

- For institutions with adequate experience, laparoscopic cholecystectomy is recommended as the first-choice surgical procedure. 
Strength of recommendation (agreement rate): 1 (100\%).

Evidence level: A.

What are the indications for open surgery?

- We recommend open surgery whenever concomitant gallbladder cancer is suspected before surgery.

Strength of recommendation (agreement rate): 2 (100\%).

Evidence level: B.

- We recommend the procedure be switched to open surgery if concomitant gallbladder cancer becomes suspected during surgery.

Strength of recommendation (agreement rate): 2 (100\%).

Evidence level: B.

- We recommend starting with open surgery or switching to open surgery when a patient with advanced inflammation that has an ambiguous anatomical relationship with cholecystocholedocholithiasis is being treated.

Strength of recommendation (agreement rate): 2 (100\%).

Evidence level: B.

\section{Commentary}

The primary treatment for symptomatic cholecystolithiasis is cholecystectomy. Laparoscopic cholecystectomy is comparable to open cholecystectomy with regard to mortality and the incidence of complications [23, 24], leads to a significantly shorter hospital stay, and is generally preferred as the first-choice surgical procedure (Fig. 1) [25-28]. It has been reported that 3.6-8\% of laparoscopic cholecystectomies are intraoperatively switched to open procedures for a variety of reasons, including technical difficulties, biliary tract damage, anesthesia problems, and device malfunction [29-32]. The switch to open cholecystectomy occurred more frequently in men than in women; in patients aged 60 years or older; and in those with a history of upper abdominal surgery, diabetes, existing cardiovascular disease, marked inflammation (i.e., acute cholecystitis), a stone impacted in the cervix of the gallbladder, pericholecystic abscess, thickened gallbladder wall, elevated alkaline phosphatase level, or a high white blood cell count. The switch was also made in patients where gallbladder cancer was found during surgery, as well as in some other patient subpopulations (Fig. 2) [29-34]. Multivariate analysis has identified the presence of acute cholecystitis and a finding of thickening of the gallbladder wall as significant independent factors for switching to open surgery $[35,36]$. However, patients with these characteristics are not necessarily outside the indication of laparoscopic cholecystectomy and these characteristics need not be considered absolute contraindications. In patients with a history of gastrectomy, it may take longer to perform a laparoscopic cholecystectomy in patients with concomitant choledocholithiasis or acute cholecystitis. However, the rate of switching to open surgery and the incidence of complications are comparable to those in patients without a previous gastrectomy. The available evidence suggests that laparoscopic cholecystectomy could become the first choice for surgery $[37,38]$.
Fig. 2 Treatment of cholecystolithiasis. It is not recommended that asymptomatic patients undergo therapy, but a conservative follow-up is recommended. Nevertheless, patients with gallbladder wall thickness or nonfunctioning, or in whom image assessment is difficult, can undergo prophylactic cholecystectomy. Symptomatic patients need treatment, and laparoscopic cholecystectomy should be a standard modality. Other modalities are optional if applicable (see the text for details)

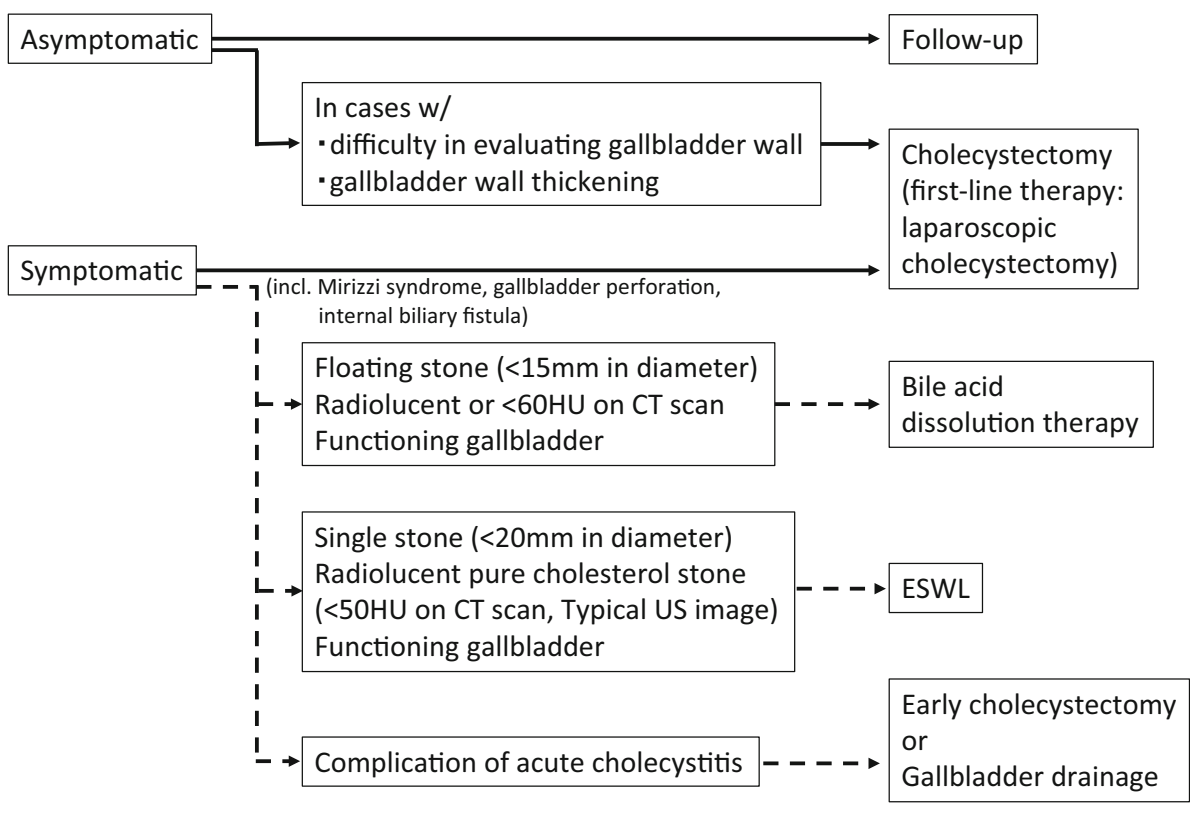

$\longrightarrow$ General treatment $\longrightarrow$ Optional treatment if applicable 
In recent years, the use of single-port access in laparoscopic cholecystectomy has increased. Randomized trials [39, 40] found that single-port laparoscopic cholecystectomy required a significantly longer procedure time than conventional laparoscopy, but the amount of bleeding and postoperative pain and the incidence of complications that occurred with the two methods did not differ [39]. In addition, postoperative quality of life was higher with the single-port technique and patients were able to return to society earlier. However, the cost was higher than with the conventional procedure [40].

Open surgery is first indicated for patients in whom concomitant gallbladder cancer is suspected preoperatively. The possibility of peritoneal dissemination resulting from intraoperative damage to the gallbladder and tumor recurrence at the port site makes open cholecystectomy the initial choice of surgical procedure for such patients [41-43]. If the patient is found to have concomitant gallbladder cancer during laparoscopic cholecystectomy, the procedure should be immediately switched to open surgery. For patients with Mirizzi syndrome, laparoscopic cholecystectomy can be selected for type I cases depending on institutional resources. Open surgery is recommended for type II cases (see CQ7). For patients with advanced inflammation and in whom the anatomical relationship cannot be clearly determined, it is acceptable to start cholecystectomy as a laparoscopic procedure, but to switch to open surgery before a complication occurs. Pregnancy is not a contraindication for minimally invasive laparoscopic cholecystectomy, as it is now considered to have minimal impact on the fetus [44], but the decision should be made on a case-by-case basis.

Laparoscopic cholecystectomy is the first-choice surgical procedure for cholecystolithiasis at institutions with adequate experience in laparoscopic surgery, but the experience of surgeons and anesthesiologists must also be considered. This becomes important when surgeons are forced to change the procedure to an open cholecystectomy (e.g., when the patient has advanced inflammation and the anatomical relationship cannot be clearly determined). The switch to open surgery should be implemented before a complication occurs.

\section{CQ4: What are the possible complications of laparoscopic cholecystectomy?}

\section{Statement}

- Intraoperative complications of laparoscopic cholecystectomy include bile duct damage, bleeding, and damage to other organs. Postoperative complications include hemorrhage, bile spillage, wound infection, shoulder pain, and subcutaneous emphysema.

\section{Commentary}

The 12th national questionnaire survey conducted by the Japan Society for Endoscopic Surgery [45], which was published outside the search period, found that laparoscopic cholecystectomy was performed in $83 \%$ of all cholecystectomy cases in 2013, making it the standard surgical procedure for cholelithiasis. Many institutions were found to indicate open cholecystectomy only for patients with a history of upper abdominal surgery or in cases suspected to involve advanced cholecystitis or gallbladder cancer. Accordingly, although it is difficult to compare the complication rates for open and laparoscopic procedures, the current consensus is that they are nearly equivalent [46, 47]. Surgical site infections have been reported to occur more often in open surgery procedures [47].

Intraoperative complications reported for a group of 452,936 patients with cholelithiasis who underwent laparoscopic cholecystectomy between 1990 and 2013 (including 19,597 single-port procedures) included bile duct injury (2876 patients, $0.63 \%$ ), bleeding that required hemostasis via open surgery (2349 patients, $0.51 \%$ ), and other organ injuries (1185 patients, $0.26 \%$ ). The procedure was switched to open cholecystectomy in 16,231 cases (3.6\%) because the anatomy was difficult to determine because of advanced inflammation, adhesion resulting from previous surgery, choledocholithiasis, or identification of another disease during surgery. Thirty-one cases with complications and accidents associated with instrument malfunction were reported in the past 2 years. Clips used in endoscopic surgery were the commonest cause of problems (17 patients, 55\%). Bile duct injury, mainly incisions or damage from disconnection after misidentification of the common bile duct as the gallbladder duct, was reported [48]. Common bleeding sites included the cystic artery, gallbladder bed (located near branches of the middle hepatic vein), and hepatic artery [46-48]. These complications were most often related to the technical competence of the surgeon, the extent of inflammation or adhesion, or surgery being contained for too long [36, 48-51].

The postoperative complications reported in the survey included 389 cases $(0.09 \%)$ that required open surgery to stop postoperative hemorrhage and 977 cases $(0.21 \%)$ of postoperatively identified bile duct injury. Common sites of postoperative hemorrhage were the cystic artery and gallbladder bed (near branches of the middle hepatic vein). The causes of postoperative bile spillage included bile duct damage that was not noticed during surgery (primarily late perforation because of heat damage), bile outflow because of failure or deviation of a clip, and, rarely, a patent duct of Luschka [48]. Between 1990 and 2013, 35 cases of port site recurrence of gallbladder cancer were reported, indicating 
the need for careful assignment of patient indications. The eighth national questionnaire survey by the Japan Society for Endoscopic Surgery reported additional complications, such as postoperative shoulder pain, wound infection, subcutaneous emphysema, and respiratory complications, but the frequency was never greater than $2 \%$. Twenty-two deaths after laparoscopic cholecystectomy were reported between 1990 and 2003 [52]. The causes directly related to the surgical procedure included injury to the great vessels or by pneumoperitoneum caused by needles and trocars (three cases), bile duct injury (three cases), and duodenal injury (one suspected case). Other causes of death included postoperative pulmonary embolism (eight cases) and postoperative pancreatitis (one case).

\section{CQ5: What are the indications for gallstone dissolution therapy?}

\section{Statement}

- As oral dissolution therapy for cholelithiasis with bile acid formulations is effective for X-ray-negative cholesterol gallstones in patients with normal gallbladder function, it should be performed in such cases. Strength of recommendation (agreement rate): 2 (100\%).

Evidence level: A.

\section{Commentary}

A medical decision analysis of various therapies for symptomatic cholecystolithiasis found that nonsurgical treatment was superior for maintaining the quality of life [53]. The effectiveness of oral dissolution therapy of $\mathrm{X}$-ray-negative cholesterol gallstones with bile acid formulations has been validated in a meta-analysis [54]. Treatment with a combination of UDCA and chenodeoxycholic acid (CDCA) for 6 months has been reported to achieve complete dissolution of gallstones with a diameter smaller than $15 \mathrm{~mm}$ in $52-62.8 \%$ of patients. A rate of $24-38 \%$ has been reported for treatment with UDCA alone [54, 55]. Although UDCA and CDCA share a common mechanism of action (i.e., increasing the solubility of cholesterol in bile) [56], the safety and efficacy of UDCA are reported to be superior [57, 58].

Since CDCA was shown to cause diarrhea at a relatively high frequency and possibly have transient effects on liver dysfunction and serum lipid levels, its use in general clinical practice has decreased [59]. Oral therapy is effective for dissolution of radiolucent cholesterol gallstones as long as the patient's gallbladder function is maintained. The efficacy of dissolution can be predicted from CT images of gallstones (greatest in stones with a CT value of less than $60 \mathrm{HU}$ ) [60-62]. The patients who will most likely benefit from oral dissolution therapy are those with multiple, floating stones with negative findings on abdominal radiography, less than $15 \mathrm{~mm}$ in diameter by ultrasonography and excretory cholangiography, and with a CT value of less than $60 \mathrm{HU}$. Floating stones should be confirmed by intravenous cholangiography as no oral contrast agents are currently commercially available. It should be noted that there are limits to therapeutic efficacy, and the dissolution effect cannot be expected with clearly calcified gallstones, with pigmented gallstones, or if the gallbladder is not functioning.

The optimal dosage and administration regimen of bile acid formulations differ, depending on the published report; for example, UDCA at $7-11.1 \mathrm{mg} / \mathrm{kg}$ body weight/day or $600 \mathrm{mg} /$ day after each meal or before bedtime [57, 58, 63, 64]; the UCDA dosage used in Japan is $600 \mathrm{mg} /$ day. If CDCA is used in combination with UDCA, CDCA at $300 \mathrm{mg} /$ day is taken after each meal. The efficacy of dissolution is assessed by diagnostic imaging after 6-12 months of medication. Since UDCA affects gallbladder contraction and increases its volume, colic pain is also expected to be reduced $[65,66]$. Although the complete dissolution rate with UDCA is not very high, UDCA has only a small number of side effects, and thus can be regarded as a safe therapeutic agent [67]. In addition, treatment with UDCA significantly reduces the likelihood of surgery and decreases the incidence of biliary pain and acute cholecystitis. Therefore, UDCA appears to be a viable option for symptomatic patients in whom dissolution therapy is indicated and who do not undergo surgery [19].

Dissolution efficacy is enhanced with the concomitant use of simvastatin, a lipid-lowering agent [68]. Meanwhile, the use of concomitant menthol or aspirin is not effective $[69,70]$. Recurrence is a problem in patients who undergo dissolution therapy, with the cumulative rate of recurrence over 12 years after dissolution reported to be $61 \%$. However, it can be reduced to $16 \%$ in patients younger than 50 years with continuing use of UDCA [71]. Despite this, UDCA is not effective for preventing gallstone formation associated with rapid weight loss or long-term intravenous hyperalimentation [72, 73].

Although dissolution therapy for cholelithiasis is effective, the evidence provided by many clinical trials is relatively old. Therefore, reassessment based on actual clinical practice in Japan needs to be performed.

\section{CQ6: What is the indication for ESWL?}

\section{Statement}

- As ESWL is effective for treatment of noncalcified cholesterol gallstones in patients with normal 
gallbladder function, it should be performed in such cases.

Strength of recommendation (agreement rate): 2 (100\%).

Evidence level: B.

\section{Criteria for indication}

1. X-ray-negative cholesterol gallstones. Stones with a CT value of less than $50 \mathrm{HU}$ and an ultrasound image characteristic of pure cholesterol gallstones are optimal.

2. Normal gallbladder function (gallbladder can be visualized on intravenous cholangiography).

\section{Commentary}

ESWL is effective for the treatment of cholesterol gallstones. Meta-analysis combined with medical decision analysis for ESWL treatment of symptomatic cholecystolithiasis found that it was inferior to laparoscopic cholecystectomy in cost-effectiveness, but superior in terms of impact on quality-adjusted life expectancy [53]. Randomized controlled trials (RCTs) comparing ESWL and cholecystectomy found both procedures to be equivalent in cost-effectiveness for the treatment of small gallstones (less than $4 \mathrm{~cm}^{3}$ ) [74], but 5-year posttreatment life expectancy of patients with a single gallstone was superior with ESWL compared with cholecystectomy [75]. In contrast, cholecystectomy had lower recurrence rates and higher rates of complete gallstone removal than ESWL [76]. Therefore, procedure selection should be based on cost-effectiveness and patient satisfaction.

There have been many reports of the effectiveness of ESWL from Japan and other countries [7, 21, 22, 77-82], including long-term outcomes over 5-10 years of followup [83-86]. The elimination rate 1 year after ESWL treatment of patients with single gallstones, gallstones smaller than $20 \mathrm{~mm}$ in diameter, and noncalcified pure cholesterol gallstones (characteristic ultrasound image, radiolucency, CT value of less than $50 \mathrm{HU}$ ) ranged from $63 \%$ to $90 \%$ [7, 21, 22, 77-84]. For calcified cholesterol gallstones, which are relatively common in Japan, the elimination rate 1 year after ESWL was reported to be $60 \%$ [87]. However, the therapeutic effect was limited, and elimination cannot be expected or achieved in patients with obviously calcified or pigmented gallstones, or without normal gallbladder function.

Treatment of cholecystolithiasis with ESWL involves oral administration of a UDCA bile acid formulation, which facilitates elimination of the pieces of crushed gallstones [20, 88, 89]. Recurrence following ESWL is a problem as the 10-year recurrence rate has been estimated to be $54-60 \%$ $[90,91]$, and patients with reduced gallbladder function are likelier to experience recurrence [92]. UDCA has also been reported to be effective for preventing recurrence [86, 87].

As it has been reported that $36 \%$ of patients treated with ESWL underwent cholecystectomy during a subsequent follow-up period [93], ESWL does not appear to be the first-choice treatment for cholecystolithiasis. Other studies have concluded that ESWL could be considered in highrisk surgery patients or in patients with Mirizzi syndrome $[94,95]$.

\section{CQ7: How should patients with Mirizzi syndrome be treated?}

\section{Statement}

- We recommend open cholecystectomy, or laparoscopic cholecystectomy if the institution has adequate experience.

Strength of recommendation (agreement rate): 2 (91\%). Evidence level: $\mathrm{C}$.

- As endoscopic biliary drainage is useful to eliminate biliary obstruction, it should be performed.

Strength of recommendation (agreement rate): 2 (100\%).

Evidence level: C.

\section{Commentary}

Mirizzi syndrome is a pathological condition involving compression of the cervix of the gallbladder by stones and stenosis of the common hepatic duct because of inflammation. It is characterized by increased occurrence of complications compared with routine surgery for cholecystolithiasis. The prevalence of Mirizzi syndrome differs by country and region. It accounts for 5.7\% (327/5673) of cholecystectomy cases in Chile [96], but only $0.18 \%$ (36/ $21,450)$ to $0.35 \%(16 / 4589)$ of cases in North America [97, 98]. The proficiency of surgeons treating patients with this disease also differs by region. The Csendes classification recognizes four major types of Mirizzi syndrome: type I is characterized by "classic" compression stenosis; types II-IV involve formation of a cholecystocholedochal fistula [95]. The type II-IV classification is determined by how much of the common bile duct is affected by the fistula; one third of the duct in type II Mirizzi syndrome, two thirds in type III Mirizzi syndrome, and the entire circumference in type IV Mirizzi syndrome. Bile duct reconstruction becomes more difficult with increases in the size of the cholecystocholedochal fistula. In some cases, difficulty performing bile duct reconstruction makes it 
necessary to perform complex surgical procedures, such as bile duct resection and choledochojejunostomy by the Roux-en-Y method [96, 99].

Mirizzi syndrome is also characterized by the difficulty of preoperative diagnosis. In one report, successful preoperative diagnosis was achieved by abdominal ultrasonography in only $20 \%(2 / 12)$ of cases, but $83.3 \%(10 / 12)$ of cases were successfully diagnosed by MRCP [99]. Another study of preoperative diagnostic performance in 13 patients with Mirizzi syndrome and 39 control patients with cholecystitis found that CT combined with MRCP was significantly better than CT alone [100]. However, there were three false-positive diagnoses of patients with Mirizzi syndrome based on findings of compression that caused by a different disease. Thus, the ability to accurately diagnose Mirizzi syndrome before surgery remains limited and needs to be addressed. A systematic review of reports evaluating laparoscopic cholecystectomy for treatment of Mirizzi syndrome found that the rate of switching to laparotomy was significantly decreased when the accuracy rate of preoperative diagnosis was high [101]. Although the review did not find any significant differences across disease types for the rate of switching to laparotomy, most investigators concluded that laparoscopic cholecystectomy could be indicated for type I Mirizzi syndrome, and that open cholecystectomy was preferable for other types. The reason was a perceived high likelihood that bile duct reconstruction would be required, or that a complication of a gallbladder-digestive tract fistula would occur, in patients with disease of type II severity or greater [96, 97, 99].

ERCP is more invasive than MRCP, but it offers good diagnostic performance and allows biliary drainage to be performed endoscopically. Laparoscopic cholecystectomy succeeded in 43 of a series of 50 patients with Mirizzi syndrome when it was performed in combination with endoscopic nasobiliary drainage (ENBD; Fig. 1) [102]. Another report found that ESWL combined with ERCP was effective for removal of stones, but involved only a small number of cases [95]. Peroral cholangioscopic lithotripsy has been reported to give good stone removal outcomes in patients with type II Mirizzi syndrome, but it cannot be viewed as a routine procedure because of large differences in institutional resources [103].

\section{CQ8: How should patients with complicated cholecystitis be treated?}

\section{Statement}

- We recommend cholecystectomy be performed early. Strength of recommendation (agreement rate): 1 (100\%).

Evidence level: A.
- For patients at high surgical risk because of comorbidities or poor general condition and for severe cases accompanied by organ damage, we recommend cholecystectomy be performed following gallbladder drainage and improvement of the patient's general condition.

Strength of recommendation (agreement rate): 1 (100\%).

Evidence level: B.

\section{Commentary}

The Japanese Society for Abdominal Emergency Medicine first published its "Clinical guidelines for acute cholangitis and cholecystitis" in 2005, followed by revised versions in 2012 and 2013 [104, 105] (literature published outside the search period). In these guidelines, the severity of acute cholecystitis is evaluated, and recommended treatment guidelines are presented according to severity. Prompt cholecystectomy within $72 \mathrm{~h}$ of onset is recommended for mild cases [106]. Elective cholecystectomy after gallbladder drainage is recommended for severe cases to improve the patient's general condition [107]. Some recent studies have validated these guidelines [108-110], and publication of large-scale prospective studies is awaited. Some issues remain for the treatment of elderly patients and high-risk surgical subpopulations [17].

Gallbladder drainage is a useful treatment for acute cholecystitis when surgery cannot be performed promptly. For example, in cases with concomitant sepsis or a highrisk disease, when there is a lack of institutional resources, or when the patient does not consent to surgery. Methods for gallbladder drainage include percutaneous transhepatic gallbladder drainage (PTGBD), which involves puncture of the gallbladder under ultrasound or CT guidance, tube placement, and continuous pus drainage (Fig. 1). Other methods include percutaneous transhepatic gallbladder aspiration (PTGBA), in which gallbladder contents are removed through an ultrasonography-guided single puncture followed by injection and removal of an antibacterial agent), and endoscopic naso-gallbladder drainage (ENGBD), which involves endoscopic insertion of a tube into the gallbladder and transpapillary drainage (Fig. 2).

PTGBD is normally selected when the infected bile in the gallbladder is viscous, and has been reported to be more effective than PTGBA [111]. The disadvantages of PTGBD include tube deviation and the restriction that the tube cannot be removed until the fistula is complete [112, 113]. PTGBA is procedurally simple, has no requirement for tube placement, and there is no risk of selfremoval by elderly patients [113]. ENGBD is slightly more technically demanding, with completion rates of about $80 \%$ 
in most reports. Although it is a safe and effective procedure, it is currently positioned as a procedure to consider in patients with accumulated ascites or bleeding tendency [114]. For gallbladder drainage, our first recommendation is PTGBD, but PTGBA should be considered because of its procedural simplicity and ENGBD should be considered for its safety. The choice should depend on the specific circumstances of the institution.

\section{CQ9: How should patients with concurrent choleperitonitis or pericystic abscess be treated?}

\section{Statement}

- We recommend emergency surgery (cholecystectomy, abdominal drainage) be performed.

Strength of recommendation (agreement rate): 1 (100\%).

Evidence level: B.

- For cases involving high-risk surgery or poor general condition, we recommend cholecystectomy be performed after emergency gallbladder drainage and improvement of the patient's general condition.

Strength of recommendation (agreement rate): 1 (100\%). Evidence level: B.

\section{Commentary}

Pericystic abscess because of the impact of acute cholecystitis on the surrounding tissue and acute cholecystitis accompanied by choleperitonitis because of gallbladder necrosis are classified as moderate-to-severe cholecystitis in the Tokyo guidelines for management of acute cholangitis and cholecystitis [105] (literature published outside the search period). Progression of severe acute cholecystitis accompanied by organ disorders (e.g., disorders of the circulatory or central nervous systems, respiratory or renal dysfunction, or blood clotting disorder) can occur even after the initial treatment, including fasting, infusion, and administration of analgesics and antibacterial agents, and can be life threatening. Therefore, the guidelines for acute cholecystitis care include emergency surgery (cholecystectomy, abdominal cavity drainage) for moderate-to-severe cholecystitis with serious local complications such as choleperitonitis and pericystic abscess, in addition to management of the patient's general condition.

In severe cases, emergency gallbladder drainage is recommended along with immediate organ support as the initial treatment. If the patient has gallstones, then cholecystectomy is recommended after the general condition has improved. A report described the outcomes of four patients with percutaneous treatment of gallbladder perforation and bile leakage because of a high risk of surgical complications [115]. Defervescence was achieved in $48 \mathrm{~h}$ after placement of an intrabiliary catheter and a drainage tube on the underside of the liver and in the vicinity of the gallbladder, and elevated leukocyte counts normalized over 4 days. One patient underwent cholecystectomy 1 month later, but the other three patients, who were asymptomatic, refused cholecystectomy despite the physician's recommendation. In another report, PTGBD was performed in 21 acute cholecystitis patients with general anesthesia risk [116]. Three patients died of sepsis within $48 \mathrm{~h}$ without any appreciable improvement. Toxemia was mitigated in 17 patients. Similarly, in a series of 18 acute cholecystitis patients who underwent percutaneous cholecystostomy as an alternative to surgery because of advanced age or serious disease [117], 16 patients exhibited immediate symptom abatement. One patient had to undergo open cholecystectomy to address persistent peritonitis symptoms, and in another patient open cholecystectomy was performed to address perforation of the large intestine because of a procedure-related complication. Akhan et al. [113], in a review of the literature, conclude that imageguided percutaneous cholecystostomy is useful for pressure reduction and contrast imaging in cholecystitis with or without stones, cholangitis, and biliary obstruction. It also provides a route for stone dissolution therapy or stone removal with a success rate of $95-100 \%$, and is accepted as a therapy for acute cholecystitis and gallbladder perforation in high-risk patients (Figs. 1, 2). Therefore, for high-risk surgery patients or those with a poor general condition, emergency gallbladder drainage is recommended with cholecystectomy after the patient's general condition has improved. In elderly patients, particularly those with underlying diseases, acute cholecystitis should be addressed with caution and due consideration of the response capacity of the institution and the patient's condition [118].

\section{Treatment of choledocholithiasis}

\section{CQ10: Should asymptomatic choledocholithiasis be treated?}

\section{Statement}

- Because there is a risk of developing cholangitis and some other conditions, we propose asymptomatic choledocholithiasis be treated.

Strength of recommendation (agreement rate): 2 $(100 \%)$.

Evidence level: A. 


\section{Commentary}

Many choledocholithiasis patients present with jaundice and abdominal pain, often complicated by acute cholangitis. Even if it is asymptomatic, choledocholithiasis can increase in severity because of concomitant acute cholangitis and can become fatal. It is generally recommended to treat asymptomatic choledocholithiasis as cholangitis symptoms such as fever and right hypochondrium pain will eventually occur [119], and all cases are subject to treatment [120]. Consequently the natural history of asymptomatic choledocholithiasis is poorly understood. Most asymptomatic choledocholithiasis cases are likely to be found through screening. It has been reported that $10-20 \%$ of patients who undergo cholecystectomy for symptomatic cholecystolithiasis concomitantly have choledocholithiasis [121]. Sarli et al. [122] compared the clinical scores of 74 cholecystolithiasis patients with choledocholithiasis with those of 74 cholecystolithiasis patients without choledocholithiasis. The scores, which included findings on abdominal ultrasonography, history of pain, aspartate aminotransferase levels, and alanine aminotransferase levels, were found to predict the presence or absence of choledocholithiasis. The investigators concluded that ERCP and MRCP should be performed if the total score is high because the concomitant presence of choledocholithiasis is highly likely. The specificity and accuracy of the prediction were $93 \%$ and $92 \%$ respectively. Jendresen et al. [123] reported that choledocholithiasis was found on MRCP in 26 of a series of 180 patients (14\%) scheduled for elective cholecystectomy for symptomatic cholecystolithiasis. Horwood et al. [124] reported that 166 of 501 consecutive patients $(33.1 \%)$ who underwent laparoscopic cholecystectomy for symptomatic cholecystolithiasis were suspected of having choledocholithiasis, and that 64 were found to be positive for stones on cholangiography. They also found that 3 of 335 patients $(0.9 \%)$ in whom choledocholithiasis was not suspected became symptomatic after surgery and were found to have residual common bile duct stones that needed to be removed. As in the patients in these reports, cholecystolithiasis patients should be evaluated for the possible concurrent presence of choledocholithiasis, and should be treated proactively whenever choledocholithiasis is confirmed, even in the absence of cholangitis (Fig. 3).

A wait-and-see approach may be taken for some patients because of advanced age, poor activities of daily living, serious underlying disease, or the treatment policy of the institution or attending physician.

\section{CQ11: How should choledocholithiasis be treated?}

\section{Statement}

- We recommend endoscopic or surgical removal of common bile duct stones.

Strength of recommendation (agreement rate): 1 (100\%).

Evidence level: B.
Fig. 3 Treatment of choledocholithiasis.Regardless of the presence or absence of symptoms, all patients should be subjected to endoscopic treatments and/or surgical techniques. The guidelines ensure flexibility in choices according to the actual clinical environment. The clinical procedures are presented in a flowchart, while taking into account that the actual clinical settings are not uniform but differ (see the text for details)

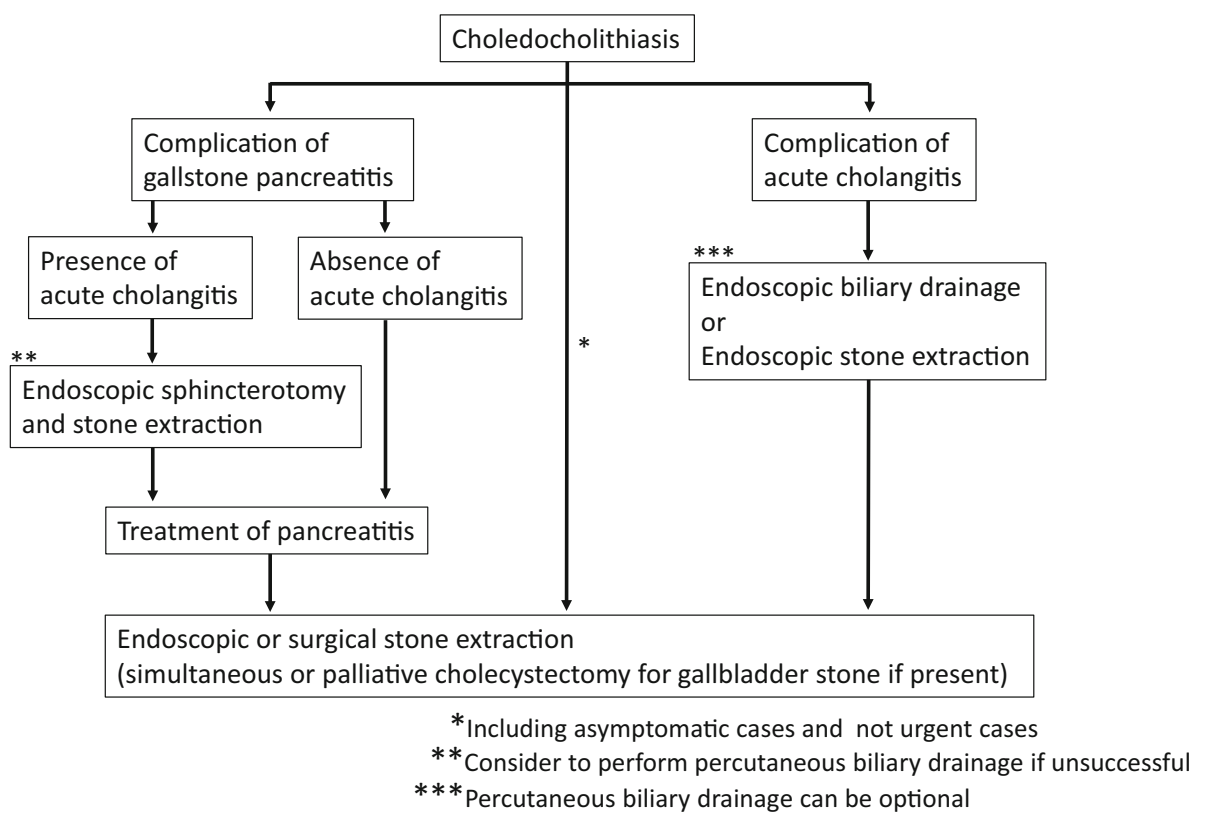




\section{Commentary}

Treatment of choledocholithiasis includes endoscopic therapy, open surgery, laparoscopic surgery, and percutaneous transhepatic treatment.

A meta-analysis comparing endoscopic treatment (in combination with cholecystectomy; two-stage treatment) of choledocholithiasis and surgery (one-stage surgery) for choledocholithiasis (12 RCTs, 1357 cases) found no differences in stone removal rate, mortality, and complication rate [125]. The surgical procedures in this meta-analysis included open (seven trials) and laparoscopic (five trials) procedures, and the subanalysis also did not reveal any differences. When cholecystectomy was performed at the same time as the treatment for choledocholithiasis, the hospital stay was reduced compared with two-stage treatment despite there being no difference in the stone removal rate [126, 127]. However, a prospective national survey conducted by the Japan Biliary Association Scientific Committee [128] (literature published outside the search period) reported that only 3 of 77 cases of choledocholithiasis were treated surgically (3.9\%), one with laparoscopic surgery and two with open choledochotomy. A similar questionnaire survey by the Japan Society for Endoscopic Surgery found that the two-stage treatment was generally performed [45]. Although each institution should choose a method with which it has the most expertise (endoscopic treatment, surgical treatment), endoscopic treatment (two-stage treatment) is currently the primary treatment in Japan.

There have not been any RCTs or meta-analyses comparing surgery (including laparoscopic surgery) and transpapillary endoscopic treatment in postcholecystectomy patients. In the prospective survey conducted by the Japan Biliary Association Scientific Committee [128], 47 of 66 patients with cholecystectomies (71.2\%) subsequently underwent transpapillary endoscopic treatment, whereas only five $(7.6 \%)$ underwent surgical treatment.

\section{CQ12-1: Endoscopic treatment. What are the selection criteria for endoscopic sphincterotomy and endoscopic papillary balloon dilation?}

\section{Statement}

- There are no strict differences in the selection criteria for endoscopic sphincterotomy (EST) and endoscopic papillary balloon dilation (EPBD). We propose that EPBD generally be performed in patients with stones less than $1 \mathrm{~cm}$ in diameter and a bleeding tendency.

Strength of recommendation (agreement rate): 2 (73\%). Evidence level: B.

\section{Commentary}

In 2009, a systematic review by Weinberg et al. [129] reported a difference in the removal rates of common bile duct stones by EST and EPBD. In contrast, a meta-analysis by Liu et al. [130] in 2011 did not detect a significant difference. However, both analyses found significantly greater use of endoscopic mechanical lithotripsy for EPBD, suggesting that EPBD is better suited for the removal of stones with smaller diameters. Although there is no difference in mortality attributable to early postoperative complications, bleeding is commoner with EST, and pancreatitis is encountered more often with EPBD. Therefore, EPBD is a valid choice for patients with a coagulation disorder, such as those with decompensated cirrhosis or taking an oral anticoagulant. However, patients should be fully informed of the increased risk of pancreatitis. Regarding long-term prognosis, there is no significant difference in the recurrence rate of choledocholithiasis (acute cholangitis), but the 2009 systematic review noted a significantly lower incidence of cholecystitis with EPBD compared with EST [1.3\% vs 5.0\%; relative risk (RR) 0.29, $95 \%$ confidence interval (CI) $0.10-0.81$ )]. Whereas posttreatment biliary infection may occur less frequently with EPBD than with EST, the choice should be made after consideration of other factors, such as stone size at the time of treatment and the type of lithotripsy required for stone removal.

Endoscopic papillary large-balloon dilation (EPLBD), which uses a large balloon with a diameter of 12-20 mm, is available as an endoscopic procedure for removing large stones [131]. EPLBD is usually performed after small EST, but there are some reports on the use of EPLBD alone. A meta-analysis of RCTs comparing EST and EPLBD found no difference in the stone removal rate $(97.35 \%$ vs $96.35 \%)$ or the use of endoscopic mechanical lithotripsy in cases involving large stones. Postoperative bleeding was significantly less likely with EPLBD (odds ratio 0.15, 95\% CI $0.04-0.50, p=0.002$ ), and no differences in the occurrence of pancreatitis, perforation, or cholangitis were noted [132]. Nevertheless, because EPLBD has only a short history of clinical use, reports of serious complications are limited. It should be used with caution, and publication bias should be considered.

\section{CQ12-2: Endoscopic treatment. What are the indications for biliary stenting?}

\section{Statement}

- We propose stenting be performed in patients with acute cholangitis and for prevention of cholangitis in patients awaiting elective treatment for stones. 
Strength of recommendation (agreement rate): 2 (100\%).

Evidence level: B.

\section{Commentary}

Short-term endoscopic biliary stenting or ENBD is performed in patients with acute cholangitis [133]. Long-term stent placement in elderly patients or in patients with serious complications that make bile duct stone removal difficult is associated with a high mortality rate because of severe cholangitis [134]. For this reason, the use of longterm stenting should be limited to patients with a limited life expectancy. However, it has been reported that longterm stenting was effective in reducing the size of stones refractory to mechanical lithotripsy, and that complete elimination was achieved in 73.7-95.6\% of cases when stone removal procedures were repeated after 3-6 months [135-139]. Even in patients given stents because stone removal had been difficult, complete stone removal may be achievable on retreatment; therefore reattempted stone removal is useful. Although RCTs have been conducted, comparison is difficult because of differences in the types of stents and oral medications used [136-139].

\section{CQ12-3: Endoscopic treatment. How should patients with biliary obstruction complicated by cholangitis be treated?}

\section{Statement}

- We recommend endoscopic biliary drainage or endoscopic surgery for common bile duct stone removal. Strength of recommendation (agreement rate): 1 (100\%).

Evidence level: B.

\section{Commentary}

Short-term stent placement (endoscopic biliary stenting, ENBD) is recommended for patients with acute cholangitis [140] (literature published outside the search period). Cholangitis can be safely treated with endoscopic biliary stenting alone without addition of EST, and stones can be treated in an elective manner. However, the hospital stay will be increased [141]. On the other hand, it has been reported that drainage, such as ENBD, is not required if stones are removed completely after EST in a one-stage procedure [142]. Short-term stenting is required to prevent cholangitis if any residual stones are suspected. The decision should be made in accordance with the surgeon's technical competence.
Comparison of drainage methods showed that the mortality with EST plus ENBD is significantly lower than that with open surgery. There is no evidence from direct comparisons of percutaneous transhepatic biliary drainage (PTBD) and endoscopic drainage, but, PTBD placement is relatively invasive and associated with procedure-related complications. However, each institution may choose the method (PTBD or PTGBD) in which it has the greater confidence. If the patient has a bleeding tendency (e.g., because of disseminated intravascular coagulation syndrome) endoscopic drainage should be the first choice.

\section{CQ12-4: Endoscopic treatment. How should patients} with pancreatitis caused by gallstones be treated?

\section{Statement}

- We recommend prompt ERCP for patients with pancreatitis caused by gallstones, and EST if it is indicated. Strength of recommendation (agreement rate): 2 (100\%).

Evidence level: B.

\section{Commentary}

In 2012, a meta-analysis of 15 RCTs with a subanalysis of two additional trials compared routine early ERCP (with or without EST) for gallstone pancreatitis with conservative treatments (including selective ERCP), and found no differences in mortality or local and systemic complications [143]. In a group of patients with cholangitis, early routine ERCP was shown to significantly reduce mortality (RR $0.20,95 \%$ CI 0.06-0.68) and local complications (RR 0.45, 95\% CI 0.20-0.99) and systemic complications (RR 0.37, 95\% CI 0.18-0.78). In a group of patients with bile duct obstruction, routine early ERCP led to significantly decreased local and systemic pancreatitis complications (RR 0.54, 95\% CI 0.32-0.91). A meta-analysis [144] of two RCTs involving early ERCP in patients with gallstone pancreatitis without concomitant cholangitis found no significant differences in complications (RR $0.95,95 \% \mathrm{CI}$ 0.74-1.22) and a tendency toward higher mortality for early ERCP (RR 1.92, 95\% CI 0.86-4.32). The usefulness of early ERCP in severe cases was supported in a previous meta-analysis [145], but recent studies have reported negative results and indicated that early ERCP is effective in patients with acute cholangitis or bile duct obstruction as a complication. However, it is difficult to accurately distinguish whether inflammatory responses, such as fever and elevated white blood cell counts, which are essential for diagnosis of cholangitis, are caused by pancreatitis or the complicating cholangitis. Therefore, if a bile duct 
obstruction or stone is found on diagnostic imaging, and it accompanies a prolonged hepatic disorder, jaundice, or a related condition, patients should undergo early ERCP as they appear to have acute cholangitis as a complication.

Although cholecystectomy is effective for preventing the recurrence of gallstone pancreatitis, no agreement has been reached regarding whether to perform it early after onset or electively. A meta-analysis [146] that analyzed 998 cases of gallstone pancreatitis (one RCT and eight cohort studies) reported that 95 patients (18\%) were rehospitalized while waiting for cholecystectomy because of biliary events, including gallstone pancreatitis (43 patients), acute cholecystitis (17 patients), and colic attack (35 patients). No differences were found in the surgical complications associated with early and elective surgery. Thus, cholecystectomy should be performed promptly after the sedation of gallstone pancreatitis. The only RCT to compare laparoscopic cholecystectomy within $48 \mathrm{~h}$ (25 patients) and conservative treatment ( 25 patients) for mild gallstone pancreatitis found no differences in the rate of switching from laparoscopic to open surgery or in perioperative complications [147]. Patients who underwent early laparoscopic cholecystectomy had a significantly shorter hospital stay (3.5 days vs 5.8 days).

\section{CQ12-5: Endoscopic treatment. How should patients} with a history of undergoing Roux-en-Y anastomosis or Billroth II gastrectomy be treated?

\section{Statement}

- We recommend endoscopic treatment. Strength of recommendation (agreement rate): 2 (100\%).

Evidence level: C.

\section{Commentary}

Patients with a history of undergoing Roux-en-Y anastomosis or Billroth II gastrectomy have generally been treated by percutaneous transhepatic cholangioscopy (PTCS) [148] because it is difficult to reach the papilla with a conventional duodenal endoscope. Double-balloon (Fig. 1) or single-balloon small-bowel endoscopes are now available, and make it possible to reach the duodenal papilla. ERCP using a long-scope small-bowel endoscope is more technically demanding than conventional ERCP because it is compatible with a limited set of instruments and does not have a forceps elevator. Moreover, complications such as perforation during insertion can occur in patients with postoperative adhesions. All relevant reports are case series, and they document $54-62 \%$ success in reaching the papilla and $100 \%$ treatment success in patients with previous Roux-en-Y anastomosis [149-152], and corresponding rates of $89 \%$ and $100 \%$ in patients with previous Billroth II gastrectomy [153-157]. These ERCP case series included only a small number of Roux-en-Y anastomosis patients (6 of 32 procedures) and Billroth II gastrectomy patients ( 9 of 43 procedures); no serious complications were reported. However, as the effects of publication bias cannot be ruled out, this procedure should be performed carefully at specialized institutions.

ERCP treatment using a duodenum endoscope inserted into the afferent loop of the Roux-en-Y anastomosis under laparoscopic assistance (LA-ERCP) has been reported [152, 158, 159], and a study comparing LA-ERCP with double-balloon endoscopes [5] has indicated that LAERCP was superior in both the papillary reach rate $(100 \%$ Vs $72 \%, p=0.005)$ and the treatment success rate $(100 \%$ vs $59 \%, p<0.001)$. However, LA-ERCP cannot be considered a routine technique for clinical use.

\section{CQ12-6 Endoscopic treatment. How should patients with biliary obstruction complicated by cholecystolithiasis be treated?}

\section{Statement}

- We recommend combined laparoscopic cholecystectomy and endoscopic removal of common bile duct stones.

Strength of recommendation (agreement rate): 1 (100\%).

Evidence level: B.

\section{Commentary}

A meta-analysis of studies comparing two-stage treatment by EST followed by laparoscopic cholecystectomy with one-stage treatment involving the removal of bile duct stones performed concurrently with laparoscopic cholecystectomy found no differences in the stone removal rate, complications, or mortality. An analysis comparing two-stage treatment by laparoscopic cholecystectomy followed by endoscopic stone removal with one-stage laparoscopic treatment also found no differences other than length of hospital stay [160]. A metaanalysis of nine RCTs including 933 patients comparing one-stage and two-stage treatment for endoscopic stone removal found no differences in stone removal rate, complication rate, mortality, or other parameters [126]. The analysis concluded that the costs of the procedures could not be compared because different methods were used to calculate the costs in different countries and 
regions. It was found that treatment policy should be determined on the basis of the availability of institutional resources and medical specialists. A prospective national survey conducted by the Japan Biliary Association Scientific Committee [128] (literature published outside the search period) found that the treatment most often used for gallbladder stones complicated by choledocholithiasis was endoscopic stone removal surgery with or without cholecystectomy $(81.8 \%, 63$ of 77 cases) Two-stage treatment was the main procedure used in clinical practice in Japan. One-stage laparoscopy-guided treatment was used in only $1.3 \%$ of cases $(1 / 77)$.

An RCT comparing a rendezvous EST technique that uses a guidewire introduced into the duodenal papilla via a transcystic route during laparoscopic cholecystectomy and EST following cholecystectomy found no differences in complications and stone removal rates, but did report that postoperative hyperamylasemia occurs at a lower rate with the rendezvous technique [161]. A meta-analysis of four RCTs involving 532 patients comparing preoperative EST and intraoperative EST using the rendezvous technique reported that post-EST complications occurred at a significantly lower rate and hospital stays were significantly shorter with intraoperative EST. There was no difference in the stone removal rate [127]. Although the intraoperative rendezvous technique facilitates bile duct cannulation and is expected to reduce the incidence of pancreatitis and other complications, it can be performed only at resource-rich institutions because it requires prolonged surgery time and an endoscopic specialist to be available in the operating room.

Complications such as cholecystitis occur over the long term if a calculous gallbladder is preserved after EST, and cholecystectomy is recommended in such cases [162]. A cohort study [163] comparing elderly patients aged 80 years or older with younger patients found a low frequency of cholecystitis in the elderly patients and concluded that cholecystectomy may be not necessary. A meta-analysis of five RCTs involving 662 patients [164] reported high death rates and gallstone-related complications in patients with preserved gallbladders, and thus recommended prophylactic cholecystectomy. However, as deaths from causes unrelated to gallstones were included, there may have been selection bias related to patient variables. A post-EST cohort study found that pneumobilia increased the risk of complications in gallbladder-preserved cases, but no data on the risk of death were shown [165, 166]. Although not removing the gallbladder after EST is clearly associated with gallstonerelated complications in the long term, it remains unknown whether this is associated with increased mortality.

\section{CQ13: What methods are there for surgical stone removal?}

\section{Statement}

- There are no strict differences in the selection criteria for open surgery and laparoscopic surgery to remove common bile duct stones. We recommend that for both methods, residual biliary stones be searched for by intraoperative cholangioscopy.

Strength of recommendation (agreement rate): 1 (100\%).

Evidence level: B.

\section{Commentary}

Although open surgery was the previous standard procedure, since the introduction of laparoscopic surgery, both are now performed. Published reports on the laparoscopic treatment of choledocholithiasis include both cohort studies and individual series [167-176]. Switching to open surgery occurred in 1.4-13\% of procedures [167-176], and transcystic stone removal was performed more frequently than choledochotomy, with the former being performed in $60-70 \%$ of cases [167-176]. All of these reports found that laparoscopic one-stage removal of common bile duct stones is noninferior to two-stage removal using a peroral endoscope and that laparoscopic surgery can be performed in most cases of choledocholithiasis. In a prospective study comparing open choledochotomy (118 patients) and laparoscopic choledochotomy (138 patients) [177] (literature published outside the search period) published in 2012, laparoscopic surgery was found to be superior to open surgery in terms of intraoperative bleeding $(20 \mathrm{~mL}$ vs $285 \mathrm{~mL}, \quad p<0.01)$, hospital stay (4.2 \pm 1.8 days vs $12.6 \pm 4.5$ days), postoperative complications $[6.5 \%$ (9/ $139)$ vs $12.7 \%(15 / 118), p<0.01]$, and wound infections [0.7\% (1/138) vs $5.9 \%(7 / 118), p<0.01]$. However, in a meta-analysis of endoscopic and surgical treatment by Clayton et al. [178], a subgroup analysis of open surgery and laparoscopic surgery found no differences in the stone removal rate, mortality, or complication rate.

The 12th questionnaire survey on endoscopic surgery [45], which was published in 2014 in Japan (literature published outside the search period), found that in 372 respondent institutions, laparoscopic stone removal was performed in all patients at 18 institutions (5\%), laparoscopic stone removal was performed in select patients at 214 institutions (58\%), and stones were removed via open surgery in all patients at 140 institutions (38\%). These results indicate that the laparoscopic removal of common 
bile duct stones has not yet become common practice in Japan, as about $40 \%$ of institutions throughout the country are still using open surgery for this procedure.

As discussed already, laparoscopic removal is possible for most common bile duct stones and has a low rate of intraoperative switching to open surgery. However, most of the evidence comes from institutions specializing in laparoscopy. The laparoscopic removal of common bile duct stones requires routine availability of both the devices used and surgeons with relevant experience. The survey results indicate that open choledochotomy is used by approximately half of the institutions in Japan, and is still of significance in routine clinical practice.

Treatment of choledocholithiasis by open surgery involves choledochotomy (one-stage suture closure or biliary drainage). Treatment of choledocholithiasis by laparoscopic surgery is achieved either by the transcystic removal of stones or by incision of the common bile duct to remove stones. The transcystic tube method is used only for common bile duct stones with a small diameter that are present in small numbers and are located on the duodenal side of the site where the three ducts merge. Otherwise, incision of the common bile duct is indicated. Caution should be exercised when common bile duct incision is considered in cases involving a duct of $10 \mathrm{~mm}$ in diameter or less because there is a risk of postoperative biliary stricture. When a common bile duct incision is performed, it is a common practice to search for residual gallstones by intraoperative cholangioscopy in addition to usual exploration of the bile duct [179]. With common bile duct incisions, as in open surgery, suturing may be performed in one stage without drainage or with drainage using a $\mathrm{C}$ tube or $\mathrm{T}$ tube. Tube insertion makes it possible to perform postoperative imaging, reduce biliary fistulae, and remove residual stones through the tube route. Although it has been reported that the use of a $\mathrm{T}$ tube leads to a high rate of serious complications, such as biliary fistulae, the removal of residual stones is easier. Although no appreciable differences have been found between one-stage suturing and T-tube insertion with regard to intraoperative bleeding, postoperative complications, and wound infection, hospital stays are shorter with one-stage suturing.

\section{Treatment of hepatolithiasis}

\section{CQ14: Should asymptomatic hepatolithiasis be treated?}

\section{Statement}

- Unless there are findings indicative of hepatatrophy or malignancy, regular follow-up observation through imaging is proposed.

Strength of recommendation (agreement rate): 2 (100\%).

Evidence level: C.

\section{Commentary}

Treatment is advised for both symptomatic and asymptomatic hepatolithiasis (Fig. 4). However, among asymptomatic patients with peripheral hepatolithiasis located in
Fig. 4 Treatment of hepatolithiasis. The flowchart ensures flexibility in choices according to the actual clinical environment (see the text for details)

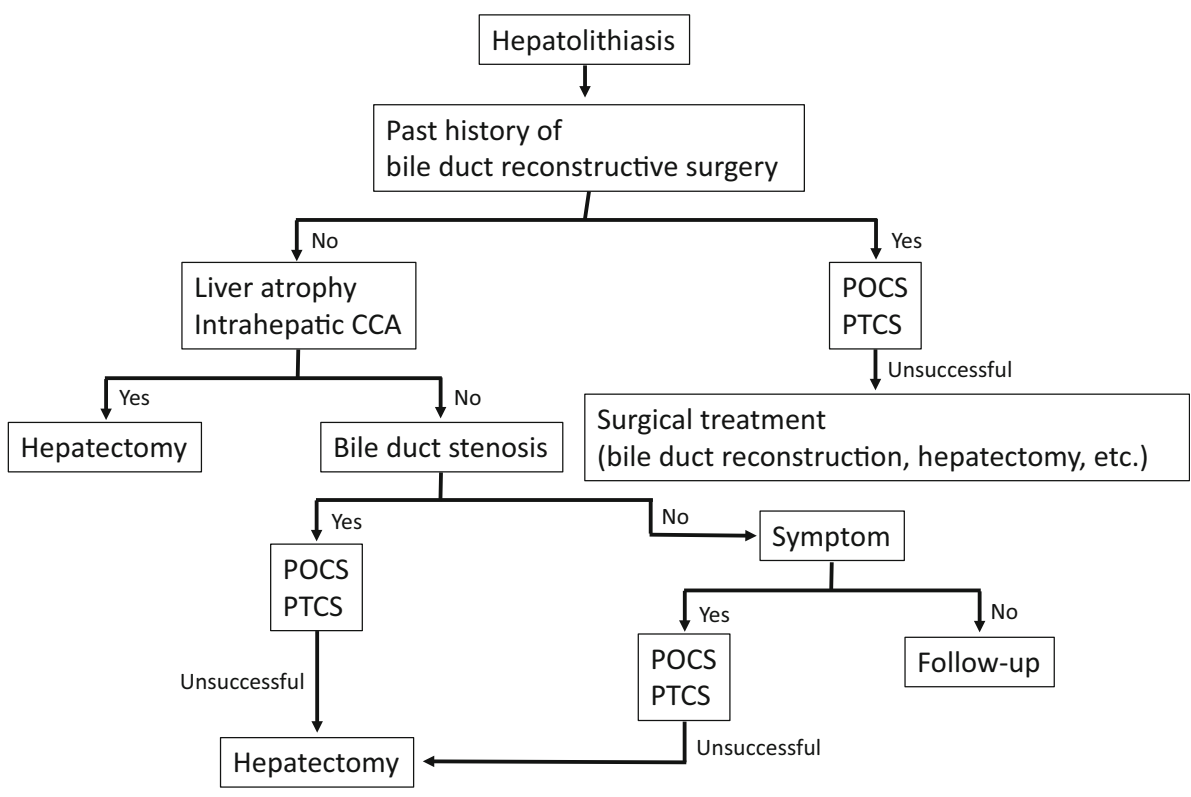

CCA, cholangiocarcinoma; POCS, Peroral cholangioscopy; PTCS, percutaneous transhepatic cholangioscopy 
the bile duct peripheral to the second-order biliary radicals and no history of biliary reconstruction, it is unlikely that patients without bile duct dilatation and strictures will become symptomatic. Specifically, regular follow-up observation via minimally invasive tests, such as abdominal ultrasonography and magnetic resonance imaging, without treatment was shown to be feasible [180]. During follow-up observation, if a neoplastic lesion is suspected or hepatatrophy and biliary strictures are observed, close examination is required. In patients with localized intrahepatic biliary strictures, even in the absence of symptoms, close examination with various diagnostic modalities is required, and biopsy with ERCP is needed to rule out malignancy [181] (literature published outside the search period). The treatment approach should be decided after careful consideration of the age, performance status, and general condition of the patient and the location of the stone [182].

\section{CQ15: What are the indications for pharmacotherapy?}

\section{Statement}

- No pharmacological agents have been proven to be effective for stone dissolution therapy; therefore, pharmacotherapy is not recommended.

Strength of recommendation (agreement rate): 2 (100\%).

Evidence level: D.

\section{Commentary}

The efficacy of pharmacotherapy for hepatolithiasis was assessed in a few studies, none of which were large-scale studies; thus, no clear conclusions could be reached.

Among different classes of hepatolithiasis, pigment stones (i.e., calcium bilirubinate stones) are the commonest, whereas cholesterol stones account for 5-10\% of all cases [183]. However, the cholesterol content of calcium bilirubinate stones is higher than that of bile duct stones, and cholesterol oversaturation of bile could be a cause of intrahepatic stone formation.

With this taken into account, drugs that are potentially effective against hepatolithiasis include fibrates that lower lipid levels, the herbal medicine inchinkoto, and UDCA, which is used as an oral agent for dissolving cholesterol stones [183]. For example, UDCA therapy resulted in the complete disappearance of hepatolithiasis in $25 \%$ of patients with Caroli syndrome and partial dissolution of gallstones in $75 \%$ of patients with Caroli syndrome, which is associated with cholesterol oversaturation of bile, and clinical remission was maintained [184]. Furthermore, in cases of hepatolithiasis associated with MDR3 deficiency, recurrence was prevented with UDCA therapy in all patients [185]. Furthermore, although UDCA may be effective against hepatolithiasis associated with cholesterol oversaturation of bile, studies on this topic included a small number of individuals, and further prospective studies with data collection on more cases are required.

Conversely, in a cohort study conducted by an investigative group supported by the Ministry of Health, Labour, and Welfare of Japan, where concurrent biliary cancer was defined as the objective variable, albeit statistically marginal, oral UDCA therapy was identified as a factor that lowered the risk of cancer onset, with a hazard ratio of 0.253 [186] (literature published outside the search period). Although several factors such as oral dosage and treatment period require further investigation, the onset of intrahepatic bile duct cancer was a prognosis predictor for hepatolithiasis, and the efficacy of UDCA therapy for hepatolithiasis in preventing cancer onset was demonstrated.

\section{CQ16: What are the indications for ESWL?}

\section{Statement}

- ESWL with concurrent peroral or percutaneous endoscopic treatment is proposed for patients without biliary strictures as well as for those with mild strictures.

Strength of recommendation (agreement rate): 2 (100\%).

Evidence level: D.

\section{Commentary}

There have been hardly any reports regarding the therapeutic outcomes of ESWL monotherapy for hepatolithiasis. Most reports have described the use of ESWL in conjunction with endoscopic transpapillary treatment or with PTCS therapy [187-189]. The purpose of ESWL is to break the stone into smaller fragments, thereby enabling its endoscopic removal. Thus, in the event of intrahepatic bile duct stenosis, the stone is assumed not to be completely removed even after successful fragmentation, and indications for ESWL should be determined with care.

During ESWL, it is often difficult to focus the shock waves on gallstones, and the target is usually located by injection of contrast medium via an ENBD tube or a PTBD tube [187, 188].

ESWL was reported to be effective in the fragmentation of stones in $60-90 \%$ of cases, and the complete stone removal rate was $60-100 \%$ with concurrent treatment 
[187, 188]. The level of fragmentation achieved by ESWL differed depending on the type of stone and was reported to be high $(92 \%)$ for cholesterol stones and low (36\%) for calcium bilirubinate stones. There are few reports of ESWL-related complications in concurrent treatment with endoscopic transpapillary treatment or PTCS therapy.

\section{CQ17: What are the indications for hepatectomy?}

\section{Statement}

- Hepatectomy is proposed for patients with concurrent intrahepatic bile duct cancer and for patients with hepatatrophy.

Strength of recommendation (agreement rate): 2 (100\%).

Evidence level: C.

- Hepatectomy is recommended for patients with symptoms in the left lobe and no history of biliary reconstruction.

Strength of recommendation (agreement rate): 2 (100\%).

Evidence level: C.

\section{Commentary}

Hepatectomy for hepatolithiasis results in lower residual stone and stone recurrence rates than other surgical treatments such as lithotomy with T-tube placement and choledochojejunostomy as well as nonsurgical treatments, such as percutaneous transhepatic cholangioscopic lithotripsy (PTCSL) and ERCP [190-195]. However, hepatolithiasis presents with a myriad of clinical manifestations, and treatment should be determined on a case-by-case basis.

In patients with concurrent or suspected intrahepatic bile duct cancer, hepatectomy is performed if the risks are acceptable. Intrahepatic bile duct cancer is a common complication of hepatolithiasis, with an incidence rate of 5.3-12.9\% [196], and is the most important clinical prognosis predictor [197]. However, because preoperative diagnosis is not possible in many cases, and there are many advanced cases, concurrent bile duct cancer should always be considered when patients with hepatolithiasis are being treated.

Surgery is also indicated for bile duct cancer, a common complication in patients with hepatatotrophy. A nationwide survey conducted in Japan revealed that in $88 \%$ of patients, the site of concurrent bile duct cancer was consistent with the site of the atrophied hepatic lobe [198]. Therefore, hepatectomy should be selected for the atrophied hepatic site.

Hepatolithiasis often affects the left lobe. In a cohort survey conducted by the Hepatolithiasis Study Group in
Japan, Cox regression analysis of patients with primary hepatolithiasis and no history of biliary reconstruction revealed that lithiasis of the left lobe was a significant risk factor for cancer onset and that hepatectomy significantly lowered the risk of cancer onset [199]. Left lobectomy is an easier and safer surgical procedure than right lobectomy; therefore, hepatectomy is usually indicated for symptomatic patients [193, 198]. Furthermore, the short-term outcomes of endoscopic surgery, which has attracted attention recently, were comparable with those of open surgery [199-201]. However, in Japan, only lateral segmentectomy is covered by the national health insurance scheme, and the indication should be determined with due care.

In bilobar hepatolithiasis, physicians often find it difficult to decide whether hepatectomy should be performed. Comparison of hepatectomy with unilobar hepatolithiasis revealed that treatment outcomes such as complete stone removal, recurrence, and complication rates differed [202-204] and that the indication for hepatectomy should be determined with consideration of remnant liver function. Furthermore, hepatectomy in combination with other therapies was useful [205].

The extent of hepatectomy is insufficient when only the site with the stone is resected. Most patients in whom hepatectomy is indicated have biliary strictures and dilatation. As residual biliary stricture and dilatation are risk factors for recurrent stone formation and bile duct cancer, resection must encompass these structures [190-204]. Therefore, extrahepatic bile duct resection with biliary reconstruction is needed in patients with concurrent cancer of the portal area and extrahepatic bile duct, with concurrent pancreatic-bile duct junction abnormalities, and with strictures extending from the portal area to the extrahepatic bile duct. However, in other patients, extrahepatic bile duct resection and biliary reconstruction should be avoided [205].

In recent years, several patients who underwent liver transplant for hepatolithiasis have been reported. However, there have been few reports targeting a large number of cases, and the long-term outcomes of this approach remain largely unclear. Therefore, at present, liver transplant should be indicated only for patients with severe cirrhosis or bilobar diffuse hepatolithiasis, and for whom none of the other approaches, including hepatectomy, are suitable [206].

\section{CQ18: What are the indications for PTCS?}

\section{Statement}

- PTCS is proposed for patients without hepatatotrophy and with or without mild biliary strictures. 
Strength of recommendation (agreement rate): 2 (100\%).

Evidence level: D.

\section{Commentary}

PTCS for hepatolithiasis succeeded in the complete removal of stones in $80-96.7 \%$ of cases when combined with electrohydraulic shock wave lithotripsy irrespective of a history of biliary reconstruction [207-209]. Unsuccessful procedures can result from intrahepatic bile duct strictures; the rate of complete stone removal in patients with particularly severe strictures was reported to be as low as $58 \%$ [208]. Takada et al. [210] performed intraoperative and postoperative biliary endoscopy via the common bile duct in 86 patients with hepatolithiasis. They reported that the treatment was successful in 59 patients $(69 \%)$ and that this approach was particularly successful (98\%) among patients without biliary strictures.

Meanwhile, studies indicated that the rate of recurrent stone formation was 35-53\% [191, 207-209], and the rate of residual stone was approximately 10-20\% [209]. Furthermore, stones could be completely removed in $3 \%$ of patients without biliary strictures [210]. Therefore, it is important to aim for complete stone removal, and longterm postoperative follow-up evaluation is needed. Furthermore, the rate of recurrence was high and the time to recurrence was short in patients with biliary strictures [207]. In addition to the limitation of PTCS efficacy in patients with biliary strictures [211], the rate of recurrence was reported to be high in patients with intrahepatic bile duct dilatation and those with Child class B or class $\mathrm{C}$ advanced cirrhosis [207, 208]. Thus, due care should be exercised in determination of PTCS indications.

Complications of PTCS include bile duct hemorrhage, cholangitis, liver abscess, and perforating injury in PTBD, with a reported complication incidence of 1.6-13.2\% [207-209, 212]. The mean number of treatments required to achieve complete stone removal is 3.9-6 [207-209], and prolongation of hospital stay also poses a problem.

\section{CQ19: What are the indications for peroral endoscopic treatment?}

\section{Statement}

- Peroral endoscopic treatment is proposed for patients without hepatatotrophy and with or without mild biliary strictures.

Strength of recommendation (agreement rate): 2 (100\%). Evidence level: D.
- Peroral endoscopic treatment is proposed for patients who have undergone biliary reconstruction.

Strength of recommendation (agreement rate): 2 (90\%). Evidence level: D.

\section{Commentary}

The indication of peroral endoscopic treatment of hepatolithiasis differs depending on the positive or negative patient history of biliary reconstruction.

In negative history of biliary reconstruction, transpapillary endoscopic treatment is indicated for patients without bile duct strictures. However, no studies with a large number of participants were conducted to assess transpapillary endoscopic treatment of hepatolithiasis without choledocholithiasis, and most reports described concurrent choledocholithiasis [212-214]. Tanaka et al. [212] conducted EST in 57 patients with concurrent hepatolithiasis and choledocholithiasis and reported that the stones were completely removed in 24 patients $(42.1 \%)$, including three patients with spontaneous stone passage. Furthermore, in subsequent long-term follow-up, no late complications were observed in patients with complete stone removal, whereas late complications were observed in ten patients with residual stones (cholangitis in seven patients, including two deaths and liver abscess in three patients). Ikeda et al. [213] reported that in long-term follow-up after EST for concurrent hepatolithiasis and choledocholithiasis, three patients died of liver abscesses. Therefore, residual stones following EST are a high risk factor for secondary biliary infection; complete stone removal is necessary by various additional approaches, and careful posttreatment follow-up assessment is needed [212, 214].

Conversely, the development of balloon endoscopy has led to an increased use of endoscopic treatment for patients with hepatolithiasis following biliary reconstruction [215, 216]. Shimatani et al. [215] used short double-balloon enteroscopy to treat seven patients with stones in a biliojejunal anastomosis after pancreaticoduodenostomy, and reported that the site of anastomosis was reached and stones were completely removed in all patients. However, the long distance to the site of anastomosis and restrictions due to the scope channel diameter make this a very challenging procedure that should be performed by experienced practitioners. Peroral endoscopic treatment of hepatolithiasis is expected to be increasingly performed, and long-term outcomes of this approach are a topic for future studies. 
CQ20: What treatments are recommended for hepatolithiasis following biliary reconstruction?

\section{Statement}

- Hepatectomy is proposed for patients with concurrent or suspected intrahepatic bile duct cancer.

Strength of recommendation (agreement rate): 2 (100\%).

Evidence level: C.

- Peroral or percutaneous endoscopic treatment is proposed.

Strength of recommendation (agreement rate): 2 (100\%).

Evidence level: D.

\section{Commentary}

There is a high rate of recurrence of hepatolithiasis following biliary reconstruction [217]. Furthermore, hepatolithiasis may be accompanied by cholangitis, liver abscess, or intrahepatic bile duct cancer. Drainage placement for patients with cholangitis can be achieved by peroral endoscopy and a percutaneous approach, but PTBD is generally indicated. However, some patients do not exhibit bile duct dilatation; in such cases, expert skill is needed. After the resolution of inflammation, the drainage tube size is increased to prepare the patient for electric hydraulicPTCSL (refer to CQ3-CQ18). Conversely, advances in balloon endoscopy resulted in an increased use of peroral endoscopy that was reported to be efficacious. However, the procedure is technically difficult and should be performed by expert practitioners. Few reports described treatment by ESWL monotherapy; instead, combination therapy with peroral endoscopic treatment and PTCS is preferred. When hepatectomy is performed for treatment of hepatolithiasis, recurrence is rare, and progress is good, if intrahepatic stones and the affected bile duct are completely removed [218]. Furthermore, the atrophied lobe is highly likely to be the primary site of onset for bile duct cancer; thus, ideal treatment is the resection of the atrophied lobe.

Acknowledgements This article was supported by a Grant-in-Aid from the Japanese Society of Gastroenterology. The authors thank the investigators and supporters for participating in the studies. The authors express special appreciation to Keishi Kanno, Hideyuki Hyogo (Hiroshima University), Toshihide Ohya (Chugoku Rosai Hospital), and Yutaka Suzuki (Kyorin University).

\section{Compliance with ethical standards}

Conflict of interest All financial relationships with enterprises, businesses, or academic institutions in the subject matter or materials discussed in this article are listed as follows: (1) Those from which the authors, the spouse, partner, or immediate relatives of the authors have received individually any income, honoraria, or any other types of remuneration: Eisai Co. Ltd., Taiho Pharmaceutical Co. Ltd., Chugai Pharmaceutical Co. Ltd. (2) Those from which the academic institutions of the authors received support (commercial/academic cooperation): Eisai Co. Ltd., MSD K.K., Otsuka Pharmaceutical Co. Ltd., Kyowa Hakko Kirin Co. Ltd., Taiho Pharmaceutical Co. Ltd., Takeda Pharmaceutical Company Limited, Mitsubishi Tanabe Pharma Corporation, Chugai Pharmaceutical Co. Ltd., Yakult Honsha Co. Ltd., Janssen Pharmaceutical K.K. The authors declare that they have no conflict of interest

\section{Appendix}

The members of the Guidelines Committee who created and evaluated the Japanese Society of Gastroenterology "Evidence-based clinical practice guidelines for cholelithiasis", are listed below.

\section{Creation Committee}

Chair: Susumu Tazuma (Department of General Internal Medicine, Hiroshima University).

Vice-Chair: Michiaki Unno (Tohoku University). Members: Yoshinori Igarashi (Divison of Gastroenterology and Hepatology Toho University Omori Medical Center), Kazuo Inui (Department of Gastroenterology, Fujita Health University), Kazuhisa Uchiyama (Department of General and Gastroenterological Surgery, Osaka Medical College), Masahiro Kai (Department of Surgery, Miyazaki Medical Association Hospital), Toshio Tsuyuguchi (Department of Gastroenterology and Nephrology, Graduate School of Medicine, Chiba University), Hiroyuki Maguchi (Center for Gastroenterology, Teine-Keijinkai Hospital), Toshiyuki Mori (Department of Surgery, Kyorin University), Koji Yamaguchi (Department of Surgery, Fujimoto General Hospital), and Shomei Ryozawa (Department of Gastroenterology, Saitama Medical University International Medical Center).

\section{Evaluation Committee}

Chair: Yuji Nimura (Aichi Cancer Center).

Vice-Chair: Naotaka Fujita (Miyagi Medical Plaza).

Members: Keiichi Kubota (Second Department of Surgery, Dokkyo Medical University), Junichi Shoda (Department of Gastroenterology, Tsukuba University), Masami Tabata (Department of Surgery, Mie University), and Tetsuya Mine (Division of Gastroenterology and Hepatology, Department of Internal Medicine, University of Tokai School of Medicine).

\section{Japanese Society of Gastroenterology}

President: Tooru Shimosegawa (Division of Gastroenterology, Tohoku University Graduate School of Medicine). 


\section{References}

1. Yoshida M, Kinoshita Y, Watanabe M, et al. JSGE clinical practice guidelines 2014: standards, methods, and process of developing the guidelines. J Gastroenterol. 2015;50:4-10.

2. Gurusamy KS, Samraj K. Cholecystectomy for patients with silent gallstones. Cochrane Database Syst Rev. 2007;1:CD006230.

3. Gurusamy KS, Davidson BR. Surgical treatment of gallstones. Gastroenterol Clin North Am. 2010;39:229-44.

4. Wittenburg H. Hereditary liver disease: gallstones. Best Pract Res Clin Gastroenterol. 2010;24:747-56.

5. Ransohoff DF, Gracie W. Treatment of gallstones. Ann Intern Med. 1993;119:606-19.

6. Halldestam I, Enell EL, Kullman E, et al. Development of symptoms and complications in individuals with asymptomatic gallstones. Br J Surg. 2004;91:734-8.

7. Sugiura N, Abe A, Saisho H. The treatment of preserving the gallbladder for gallstone. J Jpn Biliary Assoc. 2004;18:114-8.

8. Festi D, Reggiani ML, Attili AF, et al. Natural history of gallstone disease: expectant management or active treatment? results from a population-based cohort study. J Gastroenterol Hepatol. 2010;25:719-24.

9. Yano H, Kinuta M, Iwazawa T, et al. Laparoscopic cholecystectomy for asymptomatic cholelithlasis. Dig Endosc. 2003;15:190-5.

10. Mlinaric-Vrbica S, Vrbica Z. Correlation between cholelithiasis and gallbladder carcinoma in surgical and autopsy specimens. Coll Antropol. 2009;33:533-7.

11. Meirelles-Costa AL, Bresciani CJ, Perez RO, et al. Are histological alterations observed in the gallbladder precancerous lesions? Clinics (Sao Paulo). 2010;65:143-50.

12. Miyazaki M, Takada T, Miyakawa S, et al. Risk factors for biliary tract and ampullary carcinomas and prophylactic surgery for these factors. J Hepatobiliary Pancreat Surg. 2008;15:15-24.

13. Inui K, Nakazawa S, Yoshino J. A clinical study of silent gallstone and gallbladder carcinoma. Tan To Sui. 1998;19:283-6.

14. Kimura Y, Takada T, Kawarada Y, et al. Definitions, pathophysiology, and epidemiology of acute cholangitis and cholecystitis: Tokyo guidelines. J Hepatobiliary Pancreat Surg. 2007;14:15-26.

15. Vetrhus M, Soreide O, Eide GE, et al. Pain and quality of life in patients with symptomatic, non-complicated gallbladder stones: results of a randomized controlled trial. Scand J Gastroenterol. 2004;39:270-6.

16. Noro T, Yamashiro M, Hashimoto $\mathrm{H}$, et al. A treatment plan of elderly silent gallstone from the viewpoint of disease state, frequency and mode of manifestation. Surg Ther. 1992;66:371-8.

17. Moyson J, Thill V, Simoens C, et al. Laparoscopic cholecystectomy for acute cholecystitis in the elderly: a retrospective study of 100 patients. Hepatogastroenterology. 2008;55:1975-80.

18. Lee KM, Paik CN, Chung WC, et al. Risk factors for cholecystectomy in patients with gallbladder stones after endoscopic clearance of common bile duct stones. Surg Endosc. 2009;23:1713-9.

19. Tomida S, Abei M, Yamaguchi $\mathrm{T}$, et al. Long-term ursodeoxycholic acid therapy is associated with reduced risk of biliary pain and acute cholecystitis in patients with gallbladder stones: a cohort analysis. Hepatology. 1999;30:6-13.

20. Tsuchiya Y, Takanashi H, Haniya K, et al. An early gallstone clearance following repeat piezoelectric lithotripsy. J Gastroenterol Hepatol. 1994;9:597-603.
21. Sakakibara K, Hiramatu H, Okamoto N, et al. ESWL for cholecystolithiasis using spark shock waves. J Jpn Biliary Assoc. 1990;4:168-75.

22. Yamaguchi A, Tazuma S, Nishioka S, et al. The modality of nonsurgical treatments for gallstones: factors affecting gallstone recurrence after extracorporeal shock wave lithotripsy (ESWL) and posttherapeutic symptoms. J Jpn Biliary Assoc. 2004;18:108-13.

23. Keus F, de Jong JA, Gooszen HG, et al. Laparoscopic versus open cholecystectomy for patients with symptomatic cholecystolithiasis. Cochrane Database Syst Rev. 2006;4:CD006231.

24. Keus F, Gooszen HG, van Laarhovan CJ. Open, small-incision, or laparoscopic cholecystectomy for patients with symptomatic cholecystolithiasis: an overview of Cochrane Hepato-Biliary Group reviews. Cochrane Database Syst Rev. 2010;1:CD008318.

25. Barkun JS, Barkun AN, Sampalis JS, et al. Randomised controlled trial of laparoscopic versus mini cholecystectomy: the McGill Gallstone Treatment Group. Lancet. 1992;340:1116-69.

26. Attwood SE, Hill AD, Mealy K, et al. A prospective comparison of laparoscopic versus open cholecystectomy. Ann R Coll Surg Engl. 1992;74:397-400.

27. Shamiyeh A, Wayand W. Current status of laparoscopic therapy of cholecystolithiasis and common bile duct stones. Dig Dis. 2005;23:119-26.

28. Hendolin HI, Paakonen ME, Alhava EM, et al. Laparoscopic or open cholecystectomy: a prospective randomized trial to compare postoperative pain, pulmonary function, and stress response. Eur J Surg. 2000;166:394-9.

29. Wiebke EA, Pruitt AL, Howard TJ, et al. Conversion of laparoscopic to open cholecystectomy: an analysis of risk factors. Surg Endosc. 1996;10:742-5.

30. Roviaro GC, Maciocco M, Rebuffat C, et al. Complications following cholecystectomy. J $\mathrm{R}$ Coll Surg Edinb. 1997;42:324-8.

31. Giger U, Michel JM, Vonlanthen R, et al. Laparoscopic cholecystectomy in acute cholecystitis: indication, technique, risk and outcome. Langenbecks Arch Surg. 2005;390:373-80.

32. Simopoulos C, Botaitis S, Polychronidis A, et al. Risk factors for conversion of laparoscopic cholecystectomy to open cholecystectomy. Surg Endosc. 2005;19:905-9.

33. Nakagawa K, Takahashi Y, Fukamachi S, et al. Conversion to laparotomy during laparoscopic cholecystectomy. Tan To Sui. 2011;32:247-51.

34. Tokuyama Y, Osada S, Sanada Y, et al. Laparoscopic-to-open cholecystectomy conversion at a Japanese prefectural university medical school. J Jpn Coll Surg. 2009;34:562-5.

35. Alponat A, Kum CK, Koh BC, et al. Predictive factors for conversion of laparoscopic cholecystectomy. World J Surg. 1997;21:629-33.

36. Rosen M, Brody F, Ponsky J. Predictive factors for conversion of laparoscopic cholecystectomy. Am J Surg. 2002;184:254-8.

37. Sasaki A, Nakajima J, Nitta H, et al. Laparoscopic cholecystectomy in patients with a history of gastrectomy. Surg Today. 2008;38:790-4.

38. Kim J, Cho JN, Joo SH, et al. Multivariable analysis of cholecystectomy after gastrectomy: laparoscopy is a feasible initial approach even in the presence of common bile duct stones or acute cholecystitis. World J Surg. 2012;36:638-44.

39. Sinan H, Demirbas S, Ozer MT, et al. Single-incision laparoscopic cholecystectomy versus laparoscopic cholecystectomy: a prospective randomized study. Surg Laparosc Endosc Percutan Tech. 2012;22:12-6.

40. Bucher P, Pugin F, Buchs NC, et al. Randomized clinical trial of laparoendoscopic single-site versus conventional laparoscopic cholecystectomy. Br J Surg. 2011;12:1595-702. 
41. Lundberg O, Kristoffersson A. Open versus laparoscopic cholecystectomy for gallbladder carcinoma. J Hepatobiliary Pancreat Surg. 2001;8:525-9.

42. Wakai T, Shirai Y, Yokoyama N, et al. Early gallbladder carcinoma does not warrant radical resection. $\mathrm{Br} \mathrm{J}$ Surg. 2001;88:675-8.

43. Ouchi K, Mikuni J, Kakugawa Y, et al. Laparoscopic cholecystectomy for gallbladder carcinoma: results of Japanese survey of 498 patients. J Hepatobiliary Pancreat Surg. 2002;9:256-60.

44. Mori T, Abe N, Masaki T, et al. Roles of open cholecystectomy in the laparoscopic era. Tan To Sui. 2005;26:315-20.

45. Japan Society for Endoscopic Surgery. 12th nationwide survey of endoscopic surgery in Japan. J Jpn Soc Endosc Surg. 2014;19:495-640.

46. Keus F, Gooszen HG, Van Laarhoven CJ. Systematic review: open, small-incision or laparoscopic cholecystectomy for symptomatic cholecystolithiasis. Aliment Pharmacol Ther. 2009;29:359-78.

47. Halilovic H, Hasukic S, Matovic E, et al. Rate of complications and conversions after laparoscopic and open cholecystectomy. Med Arh. 2011;65:336-8.

48. Zha Y, Chen XR, Luo D, et al. The prevention of major bile duct injures in laparoscopic cholecystectomy: the experience with 13,000 patients in a single center. Surg Laparosc Endosc Percutan Tech. 2010;20:378-83.

49. Vecchio R, MacFadyen BV, Latteri S. Laparoscopic cholecystectomy: an analysis on 114,005 cases of United States series. Int Surg. 1998;83:215-9.

50. Huttl TP, Hrdina C, Kramling HJ, et al. Gallstone surgery in German university hospitals: development, complications and changing strategies. Langenbecks Arch Surg. 2001;386:410-7.

51. Panpimanmas S, Kanyaprasit K. Complications of laparoscopic cholecystectomy and their management. Hepatogastroenterology. 2004;51:9-11.

52. 18th nationwide survey of endoscopic surgery in Japan. J Jpn Soc Endosc Surg 2006;11:527-628.

53. Habu Y, Matui T, Hayashi K, et al. A clinical decision analysis to assess therapeutic modalities for symptomatic gallstones with respect to patient's quality of life and cost-effectiveness. J Jpn Soc Gastroenterol. 1993;90:2895-908.

54. May GR, Sutherland LR, Shaffer EA. Efficacy of bile acid therapy for gallstone dissolution: a meta-analysis of randomized trials. Aliment Pharmacol Ther. 1993;7:139-48.

55. Podda M, Zuin M, Battezzati PM, et al. Efficacy and safety of a combination of chenodeoxycholic acid and ursodeoxycholic acid for gallstone dissolution: a comparison with ursodeoxycholic acid alone. Gastroenterology. 1989;96:222-9.

56. Grundy SM, Lan SP, Lachin J. The effects of chenodiol on biliary lipids and their association with gallstone dissolution in the National Cooperative Gallstone Study (NCGS). J Clin Investig. 1984;73:1156-66.

57. Fromm H, Roat JW, Gonzalez V, et al. Comparative efficacy and side effects of ursodeoxycholic and chenodeoxycholic acids in dissolving gallstones: a double-blind controlled study. Gastroenterology. 1983;85:1257-64.

58. Erlinger S, Le Go A, Husson JM, et al. Franco-Belgian cooperative study of ursodeoxycholic acid in the medical dissolution of gallstones: a double-blind, randomized, dose-response study, and comparison with chenodeoxycholic acid. Hepatology. 1984;4:308-14

59. Kanno K, Tazuma S. Nonsurgical therapeutic strategies for cholecystolithiasis. Tan To Sui. 2009;30:653-6.

60. Caroli A, Favero GD, Mario FD, et al. Computed tomography in predicting gall stone solubility: a prospective trial. Gut. 1992;35:698-700.
61. Pereira SP, Veysey MJ, Kennedy C, et al. Gallstone dissolution with oral bile acid therapy: importance of pretreatment CT scanning and reasons for nonresponse. Dig Dis Sci. 1997;42:1775-82.

62. Petroni ML, Jazrawi RP, Grundy A, et al. Prospective, multicenter study on value of computerized tomography (CT) in gallstone disease in predicting response to bile acid therapy. Dig Dis Sci. 1995;40:1956-62.

63. Lanzini A, Facchinetti D, Pigozzi MG, et al. Best-buy regimen of ursodeoxycholic acid for patients with gallstones. Scand J Gastroenterol. 1991;26:551-6.

64. Jazrawi RP, Pigozzi MG, Galatola G, et al. Optimum bile acid treatment for rapid gall stone dissolution. Gut. 1992;33:381-6.

65. Forgacs IC, Maisey MN, Murphy GM, et al. Influence of gallstones and ursodeoxycholic acid therapy on gallbladder emptying. Gastroenterology. 1984;87:299-307.

66. Festi D, Frabboni R, Bazzoli F, et al. Gallbladder motility in cholesterol gallstone disease: effect of ursodeoxycholic acid administration and gallstone dissolution. Gastroenterology. 1990;99:1779-85.

67. Shibukawa N. Efficacy of ursodeoxycholic acid in gallstone patients. Tan To Sui. 2009;30:135-8.

68. Tazuma S, Kajiyama G, Mizuno T, et al. A combination therapy with simvastatin and ursodeoxycholic acid is more effective for cholesterol gallstone dissolution than is ursodeoxycholic acid monotherapy. J Clin Gastroenterol. 1998;26:287-91.

69. Lueschner M, Leuschner U, Lazarovici D, et al. Dissolution of gall stones with an ursodeoxycholic acid menthol preparation: a controlled prospective double blind trial. Gut. 1988;29:428-32.

70. Tuncer I, Harman M, Mercan R, et al. The effects of ursodeoxycholic acid alone and ursodeoxycholic acid plus lowdose acetylsalicylic acid on radiolucent gallstones. Turk J Gastroenterol. 2003;14:91-6.

71. Villanova N, Bazzoli F, Taroni F, et al. Gallstone recurrence after successful oral bile acid treatment: a 12-year follow-up study and evaluation of long-term postdissolution treatment. Gastroenterology. 1989;97:726-31.

72. Marks JW, Stein T, Schoenfield LJ. Natural history and treatment with ursodiol of gallstones formed during rapid loss of weight in man. Dig Dis Sci. 1994;39:1981-4.

73. Tsai S, Strouse PJ, Drongowski RA, et al. Failure of cholecystokinin-octapeptide to prevent TPN-associated gallstone disease. J Pediatr Surg. 2005;40:263-7.

74. Nicholl JP, Brazier JE, Milner PC, et al. Randomised controlled trial of cost-effectiveness of lithotripsy and open cholecystectomy as treatments for gallbladder stones. Lancet. 1992;340: 801-7.

75. Bass EB, Steinberg EP, Pitt HA, et al. Cost-effectiveness of extracorporeal shock-wave lithotripsy versus cholecystectomy for symptomatic gallstones. Gastroenterology. 1991;101:189-99.

76. Strasberg SM, Clavien PA. Overview of therapeutic modalities for the treatment of gallstone diseases. Am J Surg. 1993;165:420-6.

77. Sackmann M, Delius M, Sauerbruch T, et al. Shock-wave lithotripsy of gallbladder stones: the first 175 patients. N Engl J Med. 1988;318:393-7.

78. Dyrszka H, Patel S, Sanghavi B, et al. Sonographic gallstone patterns are of value in predicting the outcome of biliary lithotripsy. Am J Gastroenterol. 1991;86:1626-8.

79. Elewaut A, Crape A, Afschrift M, et al. Results of extracorporeal shock wave lithotripsy of gall bladder stones in 693 patients: a plea for restriction to solitary radiolucent stones. Gut. 1993;34:274-8.

80. Tsuchiya Y, Ishihara F, Kajiyama G, et al. Repeated piezoelectric lithotripsy for gallstones with and without 
ursodeoxycholic acid dissolution: a multicenter study. J Gastroenterol. 1995;30:768-74.

81. Haniya K, Tuchiya Y, Ohto M. Study on evaluating determinants for predicting a successful outcome of extracorporeal shock-wave biliary lithotripsy. J Jpn Biliary Assoc. 1995;9:44-53.

82. Ell C, Schneider HT, Benninger J, et al. Significance of computed tomography for shock-wave therapy of radiolucent gallbladder stones. Gastroenterology. 1991;101:1409-16.

83. Sackmann M, Pauletzki J, Sauerbruch T, et al. The Munich Gallbladder Lithotripsy Study: results of the first 5 years with 711 patients. Ann Intern Med. 1991;114:290-6.

84. Tsumita R, Sugiura N, Abe A, et al. Long-term evaluation of extracorporeal shock-wave lithotripsy for cholesterol gallstones. J Gastroenterol Hepatol. 2001;16:93-9.

85. Miyoshi H, Hattori T, Kou K, et al. Long-term outcome after extracorporeal shock wave lithotripsy for gallstones. J Jpn Soc Gastroenterol. 2001;98:1349-56.

86. Rabenstein T, Radespiel-Troger M, Hopfner L, et al. Ten years experience with piezoelectric extracorporeal shockwave lithotripsy of gallbladder stones. Eur J Gastroenterol Hepatol. 2005; 17:629-39.

87. Uchiyama F, Otsuka K, Kai M, et al. Extracorporeal shock wave lithotripsy: elimination of densely calcified gallstones and gallstones with calcified rims. Eur J Gastroenterol Hepatol. 2000;12:305-12.

88. Schoenfield LJ, Berci G, Carnovale RL, et al. The effect of ursodiol on the efficacy and safety of extracorporeal shock-wave lithotripsy of gallstones: the Dornier National Biliary Lithotripsy Study. N Engl J Med. 1990;323:1239-45.

89. Sackmann M, Ippisch E, Sauerbruch T, et al. Early gallstone recurrence rate after successful shock-wave therapy. Gastroenterology. 1990;98:392-6.

90. Janssen J, Johanns W, Weickert U, et al. Long-term results after successful extracorporeal gallstone lithotripsy: outcome of the first 120 stone-free patients. Scand J Gastroenterol. 2001;36:314-7.

91. Carrilho-Ribeiro L, Pinto-Correia A, Velosa J, et al. A ten-year prospective study on gallbladder stone recurrence after successful extracorporeal shock-wave lithotripsy. Scand J Gastroenterol. 2006;41:338-42.

92. Ochi H, Tazuma S, Kajihara T, et al. Factors affecting gallstone recurrence after successful extracorporeal shock wave lithotripsy. J Clin Gastroenterol. 2000;31:230-2.

93. Adamek HE, Rochlitz C, Von Bubnoff AC, et al. Predictions and associations of cholecystectomy in patients with cholecystolithiasis treated with extracorporeal shock wave lithotripsy. Dig Dis Sci. 2004;49:1938-42.

94. Shim CS, Moon JH, Cho YD, et al. The role of extracorporeal shock wave lithotripsy combined with endoscopic management of impacted cystic duct stones in patients with high surgical risk. Hepatogastroenterology. 2005;52:1026-9.

95. Benninger J, Rabenstein T, Farnbacher M, et al. Extracorporeal shockwave lithotripsy of gallstones in cystic duct remnants and Mirizzi syndrome. Gastrointest Endosc. 2004;60:454-9.

96. Beltran MA, Csendes A, Cruces KS. The relationship of Mirizzi syndrome and cholecystoenteric fistula: validation of a modified classification. World J Surg. 2008;32:2237-43.

97. Erben Y, Benavente-Chenhalls LA, Donohue JM, et al. Diagnosis and treatment of Mirizzi syndrome: 23-year Mayo Clinic experience. J Am Coll Surg. 2011;213:114-9.

98. Mithani R, Schwesinger WH, Bingener J, et al. The Mirizzi syndrome: multidisciplinary management promotes optimal outcomes. J Gastrointest Surg. 2008;12:1022-8.

99. Zhong H, Gong JP. Mirizzi syndrome: experience in diagnosis and treatment of 25 cases. Am Surg. 2012;78:61-5.
100. Yun EJ, Choi CS, Yoon DY, et al. Combination of magnetic resonance cholangiopancreatography and computed tomography for preoperative diagnosis of the Mirizzi syndrome. J Comput Assist Tomogr. 2009;33:636-40.

101. Antoniou SA, Antoniou GA, Makridis C. Laparoscopic treatment of Mirizzi syndrome: a systematic review. Surg Endosc. 2010;24:2237-43.

102. Zheng M, Cai W, Qin M. Combined laparoscopic and endoscopic treatment for Mirizzi syndrome. Hepatogastroenterology. 2011;58:1099-105.

103. Tsuyuguchi T, Sakai Y, Sugiyama H, et al. Long-term follow-up after peroral cholangioscopy-directed lithotripsy in patients with difficult bile duct stones, including Mirizzi syndrome: an analysis of risk factors predicting stone recurrence. Surg Endosc. 2011;25:2179-85.

104. Yokoe M, Takada T, Strasberg SM, et al. New diagnostic criteria and severity assessment of acute cholecystitis in revised Tokyo Guidelines. J Hepatobiliary Pancreat Sci. 2012;19:578-85.

105. Miura F, Takada T, Strasberg SM, et al. TG13 flowchart for the management of acute cholangitis and cholecystitis. J Hepatobiliary Pancreat Sci. 2013;20:47-64.

106. Banz V, Gsponer T, Candinas D, et al. Population-based analysis of 4113 patients with acute cholecystitis: defining the optimal time-point for laparoscopic cholecystectomy. Ann Surg. 2011;254:964-70.

107. Riall TS, Zhang D, Townsend CM Jr, et al. Failure to perform cholecystectomy for acute cholecystitis in elderly patients is associated with increased morbidity, mortality, and cost. J Am Coll Surg. 2010;210:668-77.

108. Lee SW, Yang SS, Chang CS, et al. Impact of the Tokyo guidelines on the management of patients with acute calculous cholecystitis. J Gastroenterol Hepatol. 2009;24:1857-61.

109. Iida Y, Fukunaga M, Tumura H, et al. Laparoscopic cholecystectomy for acute cholecystitis according to the Japanese guidelines. J Abdom Emerg Med. 2010;30:437-41.

110. Yoshida M, Takada T, Mayumi T, et al. The clinical evaluation of the clinical practice guidelines for the management of acute cholangitis and cholecystitis: the result of a questionnaire. J Abdom Emerg Med. 2008;28:475-80.

111. Ito K, Fujita N, Noda Y, et al. Percutaneous cholecystostomy versus gallbladder aspiration for acute cholecystitis: a prospective randomized controlled trial. AJR Am J Roentgenol. 2004;183:193-6.

112. Borzellino G, de Manzoni G, Ricci F, et al. Emergency cholecystostomy and subsequent cholecystectomy for acute gallstone cholecystitis in the elderly. Br J Surg. 1999;86:1521-5.

113. Akhan O, Akinci D, Ozmen MN. Percutaneous cholecystostomy. Eur J Radiol. 2002;43:229-36.

114. Yamashita H, Sano H, Natsume M, et al. Clinical evaluation of endoscopic naso-gallbladder drainage for gallbladder disease. Ther Res Hepatobiliary Pancreat Dis. 2008;6:5-11.

115. van Sonnenberg E, D' Agostino HB, Casola G, et al. Gallbladder perforation and bile leakage: percutaneous treatment. Radiology. 1991;178:687-9.

116. Melin MM, Sarr MG, Bender CE, et al. Percutaneous cholecystostomy: a valuable technique in high-risk patients with presumed acute cholecystitis. Br J Surg. 1995;82:1274-7.

117. Vauthey JN, Lerut J, Martini M, et al. Indications and limitations of percutaneous cholecystostomy for acute cholecystitis. Surg Gynecol Obstet. 1993;176:49-54.

118. Suzuki S, Koike N, Harada N, et al. The problem surgical treatment of acute cholangitis and cholecystitis in the elderly. J Abdom Emerg Med. 2011;31:505-10.

119. Johnson AG, Hosking SW. Appraisal of the management of bile duct stones. Br J Surg. 1987;74:555-60. 
120. Sugiyama M, Suzuki Y, Abe N, et al. Indications for surgical treatment of gallstone diseases. Surgical indication for gastrointestinal diseases in the era of endoscopic surgery. Clin Gastroenterol. 2008;23:475-80.

121. Joyce WP, Keane R, Burke GJ, et al. Identification of bile duct stones in patients undergoing laparoscopic cholecystectomy. $\mathrm{Br}$ J Surg. 1991;78:1174-6.

122. Sarli L, Costi R, Gobbi S, et al. Asymptomatic bile duct stones: selection criteria for intravenous cholangiography and/or endoscopic retrograde cholangiography prior to laparoscopic cholecystectomy. Eur J Gastroenterol Hepatol. 2000;12:1175-80.

123. Jendresen MB, Thorboll JE, Adamsen S, et al. Preoperative routine magnetic resonance cholangiopancreatography before laparoscopic cholecystectomy: a prospective study. Eur J Surg. 2002;168:690-4.

124. Horwood J, Akbar F, Davis K, et al. Prospective evaluation of a selective approach to cholangiography for suspected common bile duct stones. Ann R Coll Surg Engl. 2010;92:206-10.

125. Clayton ES, Connor S, Alexakis N, et al. Meta-analysis of endoscopy and surgery versus surgery alone for common bile duct stones with the gallbladder in situ. $\mathrm{Br} \mathrm{J}$ Surg. 2010;93:1185-91.

126. Alexakis N, Connor S. Meta-analysis of one- vs. two-stage laparoscopic/endoscopic management of common bile duct stones. HPB. 2012;14:254-9.

127. Gurusamy K, Sahay SJ, Burroughs AK, et al. Systematic review and meta-analysis of intraoperative versus preoperative endoscopic sphincterotomy in patients with gallbladder and suspected common bile duct stones. Br J Surg. 2011;98:908-16.

128. Tazuma S, Kanno K, Kubota K, et al. Report on the 2013 national cholelithiasis survey in Japan. J Hepatobiliary Pancreat Sci. 2015;22:392-5

129. Weinberg BM, Shindy W, Lo S. Endoscopic balloon sphincter dilation (sphincteroplasty) versus sphincterotomy for common bile duct stones. Cochrane Database Syst Rev. 2006;4:CD004890.

130. Liu Y, Su P, Lin S, et al. Endoscopic papillary balloon dilatation versus endoscopic sphincterotomy in the treatment for choledocholithiasis: a meta-analysis. J Gastroenterol Hepatol. 2012;27:464-71.

131. Stefanidis G, Viazis N, Pleskow D, et al. Large balloon dilation vs. mechanical lithotripsy for the management of large bile duct stones: a prospective randomized study. Am J Gastroenterol. 2011;106:278-85.

132. Feng Y, Zhu H, Chen X, et al. Comparison of endoscopic papillary large balloon dilation and endoscopic sphincterotomy for retrieval of choledocholithiasis: a meta-analysis of randomized controlled trials. J Gastroenterol. 2012;47:655-63.

133. Sharma BC, Agarwal N, Sharma P, et al. Endoscopic biliary drainage by $7 \mathrm{Fr}$ or $10 \mathrm{Fr}$ stent placement in patients with acute cholangitis. Dig Dis Sci. 2009;54:1355-9.

134. Williams EJ, Green J, Beckingham I, et al. Guidelines on the management of common bile duct stones (CBDS). Gut. 2008;57:1004-21.

135. Fan Z, Hawes R, Lawrence C, et al. Analysis of plastic stents in the treatment of large common bile duct stones in 45 patients. Dig Endosc. 2011;23:86-90.

136. Pisello F, Geraci G, Li Volsi F, et al. Permanent stenting in "unextractable" common bile duct stones in high risk patients: a prospective randomized study comparing two different stents. Langenbecks Arch Surg. 2008;393:857-63.

137. Katsinelos P, Kountouras J, Paroutoglou G, et al. Combination of endoprostheses and oral ursodeoxycholic acid or placebo in the treatment of difficult to extract common bile duct stones. Dig Liver Dis. 2008;40:453-9.

138. Lee TH, Han JH, Kim HJ, et al. Is the addition of choleretic agents in multiple double-pigtail biliary stents effective for difficult common bile duct stones in elderly patients? a prospective, multicenter study. Gastrointest Endosc. 2011;74:96-102.

139. Han J, Moon JH, Koo HC, et al. Effect of biliary stenting combined with ursodeoxycholic acid and terpene treatment on retained common bile duct stones in elderly patients: a multicenter study. Am J Gastroenterol. 2009;104:2418-21.

140. Itoi T, Tsuyuguchi T, Takada T, et al. TG13 indications and techniques for biliary drainage in acute cholangitis (with videos). J Hepatobiliary Pancreat Sci. 2013;20:71-80.

141. Lee JK, Lee SH, Kang BK, et al. Is it necessary to insert a nasobiliary drainage tube routinely after endoscopic clearance of the common bile duct in patients with choledocholithiasis-induced cholangitis? a prospective, randomized trial. Gastrointest Endosc. 2010;71:105-10.

142. Ueki T, Otani K, Fujimura N, et al. Comparison between emergency and elective endoscopic sphincterotomy in patients with acute cholangitis due to choledocholithiasis: is emergency endoscopic sphincterotomy safe? J Gastroenterol. 2009;44:1080-8.

143. Tse F, Yuan Y. Early routine endoscopic retrograde cholangiopancreatography strategy versus early conservative management strategy in acute gallstone pancreatitis. Cochrane Database Syst Rev. 2012;5:CD009779.

144. Uy MC, Daez ML, Sy PP, et al. Early ERCP in acute gallstone pancreatitis without cholangitis: a metaanalysis. JOP. 2009;10:299-305.

145. Ayub K, Imada R, Slavin J. Endoscopic retrograde cholangiopancreatography in gallstone-associated acute pancreatitis. Cochrane Database Syst Rev. 2004;4:CD003630.

146. van Baal MC, Besselink MG, Bakker OJ, et al. Timing of cholecystectomy after mild biliary pancreatitis: a systematic review. Ann Surg. 2012;255:860-6.

147. Aboulian A, Chan T, Yaghoubian A, et al. Early cholecystectomy safely decreases hospital stay in patients with mild gallstone pancreatitis: a randomized prospective study. Ann Surg. 2010;251:615-9.

148. Jeong EJ, Kang DH, Kim DU, et al. Percutaneous transhepatic choledochoscopic lithotomy as a rescue therapy for removal of bile duct stones in Billroth II gastrectomy patients who are difficult to perform ERCP. Eur J Gastroenterol Hepatol. 2009;21:1358-62.

149. Itoi T, Ishii K, Sofuni A, et al. Long- and short-type doubleballoon enteroscopy-assisted therapeutic ERCP for intact papilla in patients with a Roux-en-Y anastomosis. Surg Endosc. 2011;25:713-21.

150. Itoi $\mathrm{T}$, Ishii $\mathrm{K}$, Sofuni A, et al. Large balloon dilatation following endoscopic sphincterotomy using a balloon enteroscope for the bile duct stone extractions in patients with Roux-en-Y anastomosis. Dig Liver Dis. 2011;43:237-41.

151. Neumann H, Fry LC, Meyer F. Endoscopic retrograde cholangiopancreatography using the single balloon enteroscope technique in patients with Roux-en-Y anastomosis. Digestion. 2009;80:52-7.

152. Schreiner MA, Chang L, Gluck M, et al. Laparoscopy-assisted versus balloon enteroscopy-assisted ERCP in bariatric postRoux-en-Y gastric bypass patients. Gastrointest Endosc. 2012;75:748-56.

153. Itoi $\mathrm{T}$, Ishii $\mathrm{K}$, Itokawa $\mathrm{F}$, et al. Large balloon papillary dilation for removal of bile duct stones in patients who have undergone a Billroth II gastrectomy. Dig Endosc. 2010;22(Suppl):S98-102.

154. Lin CH, Tang JH, Cheng CL, et al. Double balloon endoscopy increases the ERCP success rate in patients with a history of Billroth II gastrectomy. World J Gastroenterol. 2010;16:4594-8.

155. Nakahara K, Horaguchi J, Fujita N, et al. Therapeutic endoscopic retrograde cholangiopancreatography using an anterior 
oblique-viewing endoscope for bile duct stones in patients with prior Billroth II gastrectomy. J Gastroenterol. 2009;3:212-7.

156. Choi CW, Choi JS, Kang DH, et al. Endoscopic papillary large balloon dilation in Billroth II gastrectomy patients with bile duct stones. J Gastroenterol Hepatol. 2012;27:256-60.

157. Kim GH, Kang DH, Song GA, et al. Endoscopic removal of bile-duct stones by using a rotatable papillotome and a largeballoon dilator in patients with a Billroth II gastrectomy (with video). Gastrointest Endosc. 2008;67:1134-8.

158. Gutierrez JM, Lederer H, Krook JC, et al. Surgical gastrostomy for pancreatobiliary and duodenal access following Roux en $\mathrm{Y}$ gastric bypass. J Gastrointest Surg. 2009;13:2170-5.

159. Lopes TL, Clements RH, Wilcox CM. Laparoscopy-assisted ERCP: experience of a high-volume bariatric surgery center (with video). Gastrointest Endosc. 2009;6:1254-9.

160. Phillips EH, Toouli J, Pitt HA, et al. Treatment of common bile duct stones discovered during cholecystectomy. J Gastrointest Surg. 2008;12:624-8.

161. Tzovaras G, Baloyiannis I, Zachari E, et al. Laparoendoscopic rendezvous versus preoperative ERCP and laparoscopic cholecystectomy for the management of cholecysto-choledocholithiasis: interim analysis of a controlled randomized trial. Ann Surg. 2012;255:435-9.

162. Boerma D, Rauws EA, Keulemans YC, et al. Wait-and-see policy or laparoscopic cholecystectomy after endoscopic sphincterotomy for bile-duct stones: a randomised trial. Lancet. 2002;360:761-5.

163. Yasui $\mathrm{T}$, Takahata $\mathrm{S}$, Kono $\mathrm{H}$, et al. Is cholecystectomy necessary after endoscopic treatment of bile duct stones in patients older than 80 years of age? J Gastroenterol. 2012;47:65-70.

164. McAlister VC, Davenport E, Renouf E. Cholecystectomy deferral in patients with endoscopic sphincterotomy. Cochrane Database Syst Rev. 2007;4:CD006233.

165. Fujimoto T, Tsuyuguchi T, Sakai Y, et al. Long-term outcome of endoscopic papillotomy for choledocholithiasis with cholecystolithiasis. Dig Endosc. 2010;22:95-100.

166. Kageoka M, Watanabe F, Maruyama Y, et al. Long-term prognosis of patients after endoscopic sphincterotomy for choledocholithiasis. Dig Endosc. 2009;21:170-5.

167. Riciardi R, Islam S, Canete JJ, et al. Effectiveness and long-term results of laparoscopic common bile duct exploration. Surg Endosc. 2003;17:19-22.

168. Petelin JB. Laparoscopic common bile duct exploration. Surg Endosc. 2003;17:1705-15.

169. Martin IJ, Bailey IS, Rhodes M, et al. Towards T-tube free laparoscopic bile duct exploration: a methodologic evolution during 300 consecutive procedures. Ann Surg. 1998;228:29-34.

170. Paganini AM, Feliciotti F, Guerrieri M, et al. Laparoscopic common bile duct exploration. J Laparoendosc Adv Surg Tech A. 2001;11:391-400.

171. Millat B, Atger J, Deleuze A, et al. Laparoscopic treatment for choledocholithiasis: a prospective evaluation in 247 consecutive unselected patients. Hepatogastroenterology. 1997;44:28-34.

172. Thompson MH, Tranter SE. All-comers policy for laparoscopic exploration of the common bile duct. Br J Surg. 2002;89:1608-12.

173. Tokumura H, Umezawa $\mathrm{A}$, Cao $\mathrm{H}$, et al. Laparoscopic management of common bile duct stones: transcystic approach and choledochotomy. J Hepatobiliary Pancreat Surg. 2002;9:206-12.

174. Ebner S, Rechner J, Beller S, et al. Laparoscopic management of common bile duct stones. Surg Endosc. 2004;18:762-5.

175. Waage A, Stromberg C, Leijonmarck CE, et al. Long-term results from laparoscopic common bile duct exploration. Surg Endosc. 2003;17:1181-5.

176. Lezoche E, Paganini AM, Carlei F, et al. Laparoscopic treatment of gallbladder and common bile duct stones: a prospective study. World J Surg. 1996;20:535-41.
177. Grubnik VV, Tkachenko AI, Ilyashenko VV, et al. Laparoscopic common bile duct exploration versus open surgery: comparative prospective randomized trial. Surg Endosc. 2012;26:2165-71.

178. Clayton ES, Connor S, Alexakis N, et al. Meta-analysis of endoscopy and surgery versus surgery alone for common bile duct stones with the gallbladder in situ. $\mathrm{Br} \mathrm{J}$ Surg. 2006;93:1185-91.

179. Campagnacci R, Baldoni A, Baldarelli M, et al. Is laparoscopic fiberoptic choledochoscopy for common bile duct stones a fine option or a mandatory step? Surg Endosc. 2010;24:547-53.

180. Tsuchiya S, Tsuyuguchi T, Sakai Y, et al. Long-term follow-up of silent stones in the peripheral bile duct. Tan To Sui. 2007;28:505.

181. Yeo D, Perini MV, Muralidharan V, et al. Focal intrahepatic structures: a review of diagnosis and management. HPB (Oxford). 2012;14:425-34.

182. Herman P, Perini MV, Pugliese V, et al. Does bilioenteric anastomosis impair results of liver resection in primary intrahepatic lithiasis? World J Gastroenterol. 2010;16:3423-6.

183. Shoda J, Tanaka N, Atomi Y. Hepatolithiasis-epidemiology, pathogenesis and medical treatment. Kan Tan Sui. 2006;52:773-82.

184. Ros E, Navarro S, Bru C, et al. Ursodeoxycholic acid treatment of primary hepatolithiasis in Caroli's syndrome. Lancet. 1993;342:404-6.

185. Rosmorduc O, Hermelin B, Poupon R. MDR3 gene defect in adults with symptomatic intrahepatic and gallbladder cholesterol cholelithiasis. Gastroenterology. 2001;120:1459-67.

186. Suzuki Y, Mori T, Yokoyama T, et al. Hepatolithiasis: analysis of Japanese nationwide surveys over a period of 40 years. J Hepatobiliary Pancreat Sci. 2014;21:617-22.

187. Ellis RD, Jenkins AP, Thompson RPH, et al. Clearance of refractory bile duct stones with extracorporeal shockwave lithotripsy. Gut. 2000;47:728-31.

188. Sackmann M, Holl J, Sauter GH, et al. Extracorporeal shock wave lithotripsy for clearance of bile duct stones resistant to endoscopic extraction. Gastrointest Endosc. 2001;53:27-32.

189. Furukawa M, Sakai T, Miyashita K, et al. Extracorporeal shock wave lithotripsy (ESWL) for treatment of hepatolithiasis report of a case. Tan To Sui. 2001;22:783-6.

190. Cheon YK, Cho YD, Moon JH, et al. Evaluation of long-term results and recurrent factors after operative and nonoperative treatment for hepatolithiasis. Surgery. 2009;146:843-53.

191. Chen $\mathrm{CH}$, Huang MH, Yang JC, et al. The treatment of isolated left-sided hepatolithiasis. Hepatogastroenterology. 2008;55:600-4.

192. Chen ZY, Gong RX, Luo YL, et al. Surgical procedures for hepatolithiasis. Hepatogastroenterology. 2010;57:134-7.

193. Uchiyama K, Yamaue H. The best choice of the treatment for hepatolithiasis to reduce residual and recurrent stones. Surgery. 2008;70:950-4.

194. Al-Sukhni W, Gallinger S, Pratzer A, et al. Recurrent pyogenic cholangitis with hepatolithiasis: the role of surgical therapy in North America. J Gastrointest Surg. 2008;12:496-503.

195. Nuzzo G, Clemente G, Giovannini I, et al. Liver resection for primary intrahepatic stones: a single-center experience. Arch Surg. 2008;143:570-4.

196. Clemente G, Giuliante F, De Rose AM, et al. Liver resection for intrahepatic stones in congenital bile duct dilatation. J Visc Surg. 2010;147:e175-80.

197. Uenishi T, Hamba H, Takemura S, et al. Outcomes of hepatic resection for hepatolithiasis. Am J Surg. 2009;198:199-202.

198. Mori T, Suzuki Y, Abe N, et al. Treatment strategy for hepatolithiasis. Gastroenterol Surg. 2011;34:1757-65.

199. Yoon YS, Han HS, Shin SH, et al. Laparoscopic treatment for intrahepatic duct stones in the era of laparoscopy: laparoscopic 
intrahepatic duct exploration and laparoscopic hepatectomy. Ann Surg. 2009;249:286-91.

200. Lai EC, Ngai TC, Yang GP, et al. Laparoscopic approach of surgical treatment for primary hepatolithiasis: a cohort study. Am J Surg. 2010;199:716-21.

201. Tu JF, Jiang FZ, Zhu HL, et al. Laparoscopic vs open hepatectomy for hepatolithiasis. World J Surg. 2010;16:2818-23.

202. Li SQ, Liang LJ, Hua YP, et al. Bilateral liver resection for bilateral intrahepatic stones. World J Gastroentarol. 2009;15:3660-3.

203. Yang T, Lau WY, Lai EC. Hepatectomy for bilateral primary hepatolithiasis: a cohort study. Ann Surg. 2010;251:84-90.

204. Li SQ, Liang LJ, Peng BG, et al. Outcomes of liver resection for intrahepatic stones: a comparative study of unilateral versus bilateral disease. Ann Surg. 2012;255:946-53.

205. Takayashiki T, Shimizu H, Kimura F, et al. Hepatolithiasis. Jpn J Clin Med 2010;(Suppl.):431-34.

206. Chen ZY, Yan LN, Zeng YY, et al. Preliminary experience with indications for liver transplantation for hepatolithiasis. Transplant Proc. 2008;40:3517-22.

207. Huang $\mathrm{MH}$, Chen $\mathrm{CH}$, Yang JC, et al. Long-term outcome of percutaneous transhepatic cholangioscopic lithotomy for hepatolithiasis. Am J Gastroenterol. 2003;98:2655-62.

208. Lee SK, Seo DW, Myung SJ, et al. Percutaneous transhepatic cholangioscopic treatment for hepatolithiasis: an evaluation of long-term results and risk factors for recurrence. Gastrointest Endosc. 2001;53:318-23.

209. Miyoshi H, Inui K, Yoshino J. Technique of common bile duct and intrahepatic stone treatment with percutaneous transhepatic cholangioscopy. Gastroenterol Endosc. 2011;53:1818-27.
210. Takada T, Uchiyama K, Yasuda H, et al. Indications for the choledochoscopic removal of intrahepatic stones based on the biliary anatomy. Am J Surg. 1996;171:558-61.

211. Ozcan N, Kahriman G, Mavili E. Percutaneous transhepatic removal of bile duct stones: result of 261 patients. Cardiovasc Intervent Radiol. 2012;35:621-7.

212. Tanaka M, Ikeda S, Ogawa Y, et al. Divergent effects of endoscopic sphincterotomy on the long-term outcome of hepatolithiasis. Gastrointest Endosc. 1996;43:33-7.

213. Ikeda S, Tanaka M, Matsumoto S, et al. Endoscopic sphincterotomy: long-term results in 408 patients with complete follow-up. Endoscopy. 1988;20:13-7.

214. Fujita R, Yamamura M, Fujita Y. Combined endoscopic sphincterotomy and percutaneous transhepatic cholangioscopic lithotripsy. Gastrointest Endosc. 1988;34:91-4.

215. Shimatani M, Matsushita M, Takaoka M, et al. Effective "short" double-balloon enteroscopy for diagnostic and therapeutic ERCP in patients with altered gastrointestinal anatomy: a large case series. Endoscopy. 2009;41:849-54.

216. Tsujino T, Yamada A, Isayama H, et al. Experiences of biliary interventions using short double-balloon enteroscopy in patients with Roux-en-Y anastomosis or hepaticojejunostomy. Dig Endosc. 2010;22:211-6.

217. Kai M, Chijiiwa K, Ohuchida J, et al. Long term outcome after treatment for hepatolithiasis. Tan To Sui. 2007;28:509.

218. Vetrone G, Ercolani G, Grazi GL, et al. Surgical therapy for hepatolithiasis: a Western experience. J Am Coll Surg. 2006;202:30. 